KAPL-P-000154

(K97029)

CONF-970568-

\title{
EFFECTS OF NEUTRON IRRADIATION ON THERMAL CONDUCTIVITY OF SiC-BASED COMPOSITES AND MONOLITHIC CERAMICS
}

\author{
D.J.Senor, J.J. Woods
}

May 1997

DISTABDUTON OF THS DOCUAENT IS UNLITED p

\section{MASTER}

\section{NOTICE}

This report was prepared as an account of work sponsored by the United States Government. Neither the United States, nor the United States Department of Energy, nor any of their employees, nor any of their contractors, subcontractors, or their employees, makes any warranty, express or implied, or assumes any legal liability or responsibility for the accuracy, completeness or usefulness of any information, apparatus, product or process disclosed, or represents that its use would not infringe privately owned rights.

Operated for the U. S. Department of Energy by KAPL, Inc. a Lockheed Martin company 


\section{DISCLAIMER}

This report was prepared as an account of work sponsored by an agency of the United States Government. Neither the United States Government dor any agency thereof, nor any of their employees. makes any wartanty, express or implied. of assumes any legal liability or responsibility for the accuracy, coropletedess. or usefulness of any information, apparatus, product, or process disclosed or represents that its use would not infringe privately owned rights. Referesce beres wo any specific commercial product, process, or service by trade name. tradernart. manufac. turer, or otherwise does not necessarily constitute or imply its endorsenent, recom. mendation, or favoring by the United States Government or any ageacy thereof. The views and opinions of authors expressed herein do aor becessanly sute or reflect those of the United States Goverament or any agency cbereor. 


\section{DISCLAIMER}

Portions of this document may be illegible in electronic image products. Images are produced from the best available original document. 


\title{
Effects of Neutron Irradiation on Thermal Conductivity of SiC-Based Composites and Monolithic Ceramics
}

\author{
D.J. Senora, G.E. Youngblooda, C.E. Mooreb, D.J. Trimblec, and J.J. Woodsd \\ aPacific Northwest National Laboratory, Richland, WA \\ bAuburn University, Auburn, AL \\ cWestinghouse Hanford Company, Richland, WA \\ dLockheed Martin, Schenectady, NY
}

\begin{abstract}
A variety of $\mathrm{SiC}$-based composites and monolithic ceramics were characterized by measuring their thermal diffusivity in the unirradiated, thermal annealed, and irradiated conditions over the temperature range 400 to $1000^{\circ} \mathrm{C}$. The irradiation was conducted in the EBR-II to doses of 33 and 43 dpa-SiC (185 EFPD) at a nominal temperature of $1000^{\circ} \mathrm{C}$. The annealed specimens were held at $1010^{\circ} \mathrm{C}$ for 165 days to approximately duplicate the thermal exposure of the irradiated specimens. Thermal diffusivity was measured using the laser flash method, and was converted to thermal conductivity using density data and calculated specific heat values. Exposure to the 165 day anneal did not appreciably degrade the conductivity of the monolithic or particulate-reinforced composites, but the conductivity of the fiberreinforced composites was slightly degraded. The crystalline SiC-based materials tested in this study exhibited thermal conductivity degradation after irradiation, presumably caused by the presence of irradiation-induced defects. Irradiationinduced conductivity degradation was greater at lower temperatures, and was typically more pronounced for materials with higher unirradiated conductivity. Annealing the irradiated specimens for one hour at $150^{\circ} \mathrm{C}$ above the irradiation temperature produced an increase in thermal conductivity, which is likely the result of interstitial-vacancy pair recombination. Multiple post-irradiation anneals on CVD $\beta$-SiC indicated that a portion of the irradiation-induced damage was permanent. A possible explanation for this phenomenon was the formation of stable dislocation loops at the high irradiation temperature and/or high dose that prevented subsequent interstitial/vacancy recombination.
\end{abstract}




\section{INTRODUCTION}

Silicon carbide $(\mathrm{SiC})$ has long been considered an attractive material for use in a fusion reactor environment because of its excellent high-temperature strength and thermal conductivity, dimensional stability during irradiation, and low neutron activation. However, monolithic $\mathrm{SiC}$ is not a suitable choice for structural applications due to its brittle nature. In contrast, $\mathrm{SiC}$-fiber-reinforced/SiC-matrix $\left(\mathrm{SiC}_{\mathrm{f}} / \mathrm{SiC}\right)$ composites have recently been shown to exhibit non-catastrophic failure modes analogous to the plastic deformation exhibited by traditional metallic materials $[1,2]$. As a result, $\mathrm{SiC}_{\mathrm{f}} / \mathrm{SiC}$ composites are under consideration as candidate structural materials in several fusion reactor concepts. However, several issues that must be addressed before their inclusion in detailed designs are optimization of constituent materials, refinement of fabrication and processing methods, and characterization of the effect of irradiation on material properties. The present study focused on a variety of SiC-based materials that were characterized by measuring their thermal diffusivity in the unirradiated, thermal annealed and irradiated conditions.

\section{THEORY}

\subsection{Thermal diffusivity}

The laser flash method was used to measure thermal diffusivity [3,4]. Under ideal conditions (instantaneous and spatially uniform energy pulse absorption, onedimensional conduction through the specimen, no heat loss to the surroundings, and homogeneous and isotropic material), the expected temperature rise of the back surface of the specimen may be calculated analytically for a given value of thermal diffusivity. By comparing the expected and measured temperature profiles, the thermal diffusivity of the material may be corrected for non-ideal conditions. A numerical technique was used to reduce the thermal diffusivity data [5], which incorporated corrections for finite pulse-time effects $[6,7,8]$ and radiative heat loss $[9,10]$. Correction factors not incorporated in this technique include those for twodimensional conduction $[6,11]$, convective heat losses $[9,11]$, spatial nonuniformity of the heating pulse [11], and pulse-shape effects [12]. In general, these corrections are either irrelevant or have minimal impact using the laser flash method. Additionally, in planar weave fiber-reinforced composites like those tested in this study, differences in radial and through-thickness thermal diffusivity caused by the anisotropy of the fiber architecture may impact the validity of assuming onedimensional conduction.

\subsection{Specific heat}

Calculations of specific heat were made using the Debye theory, which models the atoms of a crystalline solid as a collection of coupled harmonic oscillators vibrating about their lattice sites [13]. For ceramic materials at low to moderate 
temperatures, these atomic vibrations constitute the dominant contribution to the internal energy of the solid. The internal energy of the solid may be determined using statistical methods to yield an expression for the heat capacity as a function of temperature

$$
C_{v}=9 R\left(\frac{T}{\Theta_{D}}\right)^{3} \int_{0}^{\frac{\Theta_{D}}{T}} \frac{z^{4} \mathrm{e}^{z}}{\left(\mathrm{e}^{z}-1\right)^{2}} \mathrm{~d} \mathrm{z},
$$

where $R$ is the universal gas constant, and $\Theta_{\mathrm{D}}$ is defined as the Debye temperature, which represents a characteristic property of the material. Strictly speaking, the Debye temperature is itself a function of temperature, but at temperatures above $\Theta_{\mathrm{D}} / 2$, it may be regarded as constant. Heat capacity at constant volume was calculated by evaluating Equation (1) over the temperature range 25 to $1200^{\circ} \mathrm{C}$ for each constituent element of a material using appropriate Debye temperatures taken from the literature [14]. The heat capacity calculated for each constituent was combined in the proper mass fraction to produce an aggregate molar heat capacity at constant volume, as prescribed by the Neumann-Kopp rule [15]. However, the heat capacity at constant pressure $\left(C_{p}\right)$ was of more interest than $C_{v}$, because it allowed for thermal expansion of the material. The heat capacity at constant pressure was obtained from $C_{v}$ by adding to it a ratio called the dilation term, which is a function of temperature, volumetric thermal expansion, and isothermal compressibility [13]. The data needed to calculate the dilation term typically are not readily available; however, the term is always positive, and experimental observations have indicated that it typically represents approximately $10 \%$ of the value of $C_{p}$ [13]. Therefore, the dilation term was assumed constant, and $C_{p}$ was estimated by multiplying $C_{v}$ by a factor of 1.10. To convert from heat capacity to specific heat, the aggregate $C_{p}$ was divided by the aggregate molecular weight of each material.

\subsection{Thermal conductivity}

Room temperature measurements of bulk density calculated from mass and dimensional measurements were extrapolated to higher temperatures using $\mathrm{SiC}$ thermal expansion data from the literature [16]. Thermal conductivity was then calculated as a function of temperature from thermal diffusivity data $(\alpha)$, density data $(\rho)$, and specific heat calculations $\left(c_{\mathrm{p}}\right)$ using the expression

$$
k=\alpha c_{p} \rho
$$




\section{EXPERIMENTAL}

\subsection{Materials}

Table 1 presents a summary of the materials tested in this study. The densities listed typically represent single measurements obtained by measuring and weighing unirradiated samples. The baseline composite was fabricated from Nicalon CG fiber reinforcement with a $150 \mathrm{~nm}$ thick pyrolytic carbon (PyC) interface coating. The matrix consisted of chemical vapor infiltrated (CVI) SiC. This composite (Nicalon/150 nm PyC/CVI SiC) was fabricated with two different fiber architectures, $0^{\circ} / 90^{\circ}$ and $0^{\circ} / \pm 86^{\circ}$. The CVI SiC matrix material was nominally fully crystalline $\beta$-SiC. Both of the architectures had total fiber volume fractions near 0.40 , with approximately $10 \%$ bulk porosity distributed predominantly as planar voids between laminae.

Table 1. Materials included in the test matrix.

\begin{tabular}{|l|c|c|c|c|l||}
\hline Reinforcement & $\begin{array}{c}\text { Fiber } \\
\text { Architecture }\end{array}$ & Interface & Matrix & $\begin{array}{c}\text { Measured } \\
\text { Density } \\
\left(\mathrm{g} / \mathrm{cm}^{3}\right)\end{array}$ & \multicolumn{1}{|c|}{ Vendor } \\
\hline \hline Nicalon CG & $0^{\circ} / 90^{\circ}$ & $150 \mathrm{~nm}$ PyC & CVI SiC & 2.48 to 2.63 & DuPont \\
\hline Nicalon CG & $0^{\circ} / \pm 86^{\circ}$ & $150 \mathrm{~nm}$ PyC & CVI SiC & 2.68 & DuPont \\
\hline Nicalon CG & $0^{\circ} / 90^{\circ}$ & $150 \mathrm{~nm}$ PyC & PIP SiC & 2.20 & Dow Corning \\
\hline Nicalon CG & $0^{\circ} / 90^{\circ}$ & $150 \mathrm{~nm}$ PyC & Blackglas & 2.04 & Allied Signal \\
\hline Nicalon CG & $0^{\circ} / 90^{\circ}$ & $15 \mathrm{~nm}$ PyC & PIP SiC & 2.18 & Dow Corning \\
\hline Nicalon CG & $0^{\circ} / 90^{\circ}$ & $150 \mathrm{~nm}$ BN & PIP SiC & 2.21 & Dow Corning \\
\hline Tyranno & $0^{\circ} / 90^{\circ}$ & $150 \mathrm{~nm}$ PyC & PIP SiC & 2.10 & Dow Corning \\
\hline HPZ & $0^{\circ} / 90^{\circ}$ & $150 \mathrm{~nm}$ PyC & PIP SiC & 2.12 & Dow Corning \\
\hline SiC $_{\mathrm{w}}$ & - & - & CVI SiC & 2.72 & ORNL \\
\hline $\mathrm{SiC}_{\mathrm{p}}$ & - & - & Blackglas & 2.73 & Allied Signal \\
\hline & - & - & CVD $\beta-S i C$ & 3.25 & Morton \\
\hline- & - & - & Hexoloy SA & 3.16 & Carborundum \\
\hline- & - & - & Hexoloy SX & 3.19 & Carborundum \\
\hline
\end{tabular}

Two alternate matrix materials were studied in combination with Nicalon CG fiber reinforcement: Polymer Impregnated Precursor (PIP) SiC and Blackglas SiC. These composites were fabricated by liquid polymer infiltration followed by pyrolysis to convert the matrix to a ceramic. The resulting matrices were carbonand oxygen-rich and at least partially amorphous. The polymer-derived matrix 
composites were fabricated with a $0^{\circ} / 90^{\circ}$ fiber architecture and a fiber volume fraction of approximately 0.40 . The Nicalon/PIP SiC and Nicalon/Blackglas composites contained less open porosity than the Nicalon CVI SiC composites $(<5 \%$ according to vendor specifications), but had lower densities due to the lower degree of matrix crystallinity and, in some cases, a significant amount of closed porosity. Two alternate fibers (Tyranno and HPZ) and two alternate interfaces (15 nm PyC and $150 \mathrm{~nm} \mathrm{BN}$ ) also were tested in combination with the PIP SiC matrix. The density of these composites were somewhat lower than the Nicalon/PIP SiC composite due to the lower densities of the fiber reinforcement. The fiber architecture, fiber volume fraction, and porosity of these composites were comparable to the Nicalon/PIP SiC material.

Two SiC-based particulate reinforced composites were studied: $\mathrm{SiC}_{\mathrm{w}} / \mathrm{CVI}$ and $\mathrm{SiC}_{\mathrm{p}} /$ Blackglas. The $\mathrm{SiC}_{\mathrm{w}}$ reinforcement was pressed in a random orientation and infiltrated using forced CVI. The particulate reinforcement in the Blackglas matrix composite was spheroidal $\mathrm{SiC}$ powder, which was mixed with the liquid polymer matrix precursor in a slurry before pyrolyzing. Both particulate-reinforced composites had reinforcement volume fractions of approximately 0.40 .

The monolithic ceramics in the test matrix included chemical vapor deposited (CVD) $\beta$-SiC, and Hexoloy SA and SX. The CVD $\beta$-SiC was reported to be $99.99 \%$ pure, fully dense, and fully crystalline. The Hexoloy samples were sintered $\alpha-S i C$ with small amounts of additives used as sintering aids $\left(\mathrm{Y}_{2} \mathrm{O}_{3}\right.$ in Hexoloy $\mathrm{SX}$ and $\mathrm{B}$ in Hexoloy SA).

\subsection{Irradiation and thermal exposure}

The irradiation was conducted in the EBR-II, in an inert gas atmosphere at approximately $1000^{\circ} \mathrm{C}$, for 185 effective full power days (EFPD), resulting in fluences of $2.6 \times 10^{22}$ and $3.4 \times 10^{22} \mathrm{n} / \mathrm{cm}^{2}(\mathrm{E}>0.1 \mathrm{MeV})$. The higher fluence value was determined from neutron activation analysis of a dosimetry capsule; the lower fluence was extrapolated based on the known axial flux profile in the EBR-II. The fluences correspond to doses of 33 and $43 \mathrm{dpa}-\mathrm{SiC}$ in the EBR-II neutron spectrum, assuming threshold displacement energies of $25 \mathrm{eV}$ for $\mathrm{Si}$ and $31 \mathrm{eV}$ for $\mathrm{C}$. The annealed specimens were held at $1010^{\circ} \mathrm{C}$ for 165 days in an inert gas atmosphere to approximately duplicate the thermal exposure of the irradiated specimens.

\subsection{Thermal diffusivity}

The samples fabricated from fiber-reinforced composites were oriented such that diffusivity was measured perpendicular to the plane of the fiber weave. The pulsed energy source used in this study was a ruby laser with a rated output of $25 \mathrm{~J}$ and a nominal pulse length of $1.4 \mathrm{~ms}$. The laser beam was focused and aligned using a series of precision optics to ensure maximum specimen coverage. The disk-shaped specimen (10 mm diameter $\times 1$ to $3 \mathrm{~mm}$ thick) was held in a cylindrical lavite holder with tungsten retaining rings. Specimen coatings were typically not used. The 
holder was positioned inside a refractory metal alignment tube in the center of a tungsten-mesh tube furnace. The furnace was purged with flowing argon at a rate of approximately $10 \mathrm{~cm}^{3} / \mathrm{s}$ and a pressure of approximately $0.11 \mathrm{MPa}$. The furnace temperature was monitored using a W-5Re/W-26Re thermocouple located approximately $1 \mathrm{~cm}$ from the specimen. The specimen temperature was correlated with observed furnace temperatures by a series of separate measurements with a calibration thermocouple in place of the specimen. The accuracy of the calculated specimen temperatures was confirmed to be $\pm 5^{\circ} \mathrm{C}$, based on thermal diffusivity qualification tests using Armco Iron and round-robin tests using Morton CVD $\beta-\mathrm{SiC}$.

The relative temperature rise on the back surface of the specimen was measured by a cryogenic InSb infrared detector. Neutral density filters were used when necessary to reduce the ambient noise level of the detector. The signal from the detector was passed through a shielded coaxial cable to an amplifier and a digital oscilloscope that recorded temperature data at $1 \mathrm{~ms}$ intervals. The data were transferred from the oscilloscope to a computer through an analog-to-digital data acquisition board. Data reduction calculations were performed using customtailored software integrated with the data acquisition board. An optical trigger marked the time-zero reference point at the moment the laser pulse was emitted by inserting a negative voltage spike in the recorded data. The baseline temperature was determined from approximately $50 \mathrm{~ms}$ of steady-state signal before the trigger spike. The raw data were filtered and smoothed to yield a representative curve with extraneous noise removed to the maximum extent possible. The peak temperature was determined from the maximum value of the filtered and smoothed data.

A typical test series consisted of thermal diffusivity measurements at $200^{\circ} \mathrm{C}$ intervals, both ascending and descending, over the range 400 to $1000^{\circ} \mathrm{C}$. Thermal annealed and irradiated specimens were held for 1 hour at $1150^{\circ} \mathrm{C}$ after making the ascending temperature measurements and before making the descending temperature measurements. At other measurement temperatures, the furnace was allowed to equilibrate approximately 20 to 30 minutes (until the observed temperature changed by less than $0.5^{\circ} \mathrm{C} / \mathrm{min}$ ) before making diffusivity measurements. Each diffusivity data point represents the average value of at least three separate measurements at each temperature. The typical precision of the apparatus was approximately $\pm 4 \%$ over the temperature range 150 to $1450^{\circ} \mathrm{C}$. Qualification tests using Armco Iron indicated accuracy to within $\pm 10 \%$ over the temperature range 500 to $900^{\circ} \mathrm{C}$, based on comparisons with reference data [16]. Round-robin tests using an identical sample of Morton CVD B-SiC resulted in agreement of better than $\pm 7 \%$ over the temperature range of 400 to $1000^{\circ} \mathrm{C}$.

\subsection{Specific heat}

Figure 1 provides a comparison of the specific heat of pure, stoichiometric SiC calculated using the Debye theory with experimental data taken from the literature [16]. Agreement between the calculated and experimental values is good over the temperature range of 25 to $1200^{\circ} \mathrm{C}$, which is remarkable considering that the 
literature data are representative of relatively low-purity material (typically $\approx 95 \%$ $\mathrm{SiC}$ ). This insensitivity to minor constituents is further demonstrated by the fact that calculated specific heat values for CVD $\beta-S i C$, Hexoloy SA, and Hexoloy SX were indistinguishable, despite the presence of $\mathrm{B}$ and $\mathrm{Y}_{2} \mathrm{O}_{3}$ sintering aids in Hexoloy SA and $S X$, respectively.

Specific heat values were calculated for the fiber- and particulate-reinforced composites using an approach analogous to that described for the monolithic materials. Fiber compositions were taken from the nominal values reported by their respective vendors. The CVI SiC matrix was assumed to be pure, stoichiometric $\mathrm{SiC}$, and the polymer-derived matrices were assumed to have the same composition as Nicalon CG fiber. Variations in the fiber/matrix interface material had no effect on the calculated values of specific heat. The SiC whiskers and particles were assumed to be pure, stoichiometric SiC. In general, the calculated specific heat values for the composites were relatively insensitive to significant compositional differences. The maximum variation between any two composites over the temperature range 400 to $1000^{\circ} \mathrm{C}$ was approximately $15 \%$.

\section{RESULTS AND DISCUSSION}

\subsection{Fiber reinforced composites}

In Figure 2, the calculated thermal conductivity values for unirradiated Nicalon/150 nm PyC/CVI SiC composites with two different fiber architectures and slightly different bulk densities are presented. The error bars represent only the experimental scatter associated with the thermal diffusivity measurements. In general, the values obtained in the present study decrease with increasing temperature and agree with the Hollenberg, et al. [1] results. As expected, no significant difference is discernible in the through-thickness thermal conductivity of composites with the $0^{\circ} / 90^{\circ}$ and $0^{\circ} / \pm 86^{\circ}$ fiber architectures. The composites with higher bulk densities in general have higher thermal conductivity values. The spread in the thermal conductivity data for the various specimens is approximately $10 \%$, which generally correlates with the $8 \%$ spread in density values. The uniformity of the variation over the entire temperature range suggests that the variation is caused by microstructural differences and not impurity effects. However, the distribution orientation and shape of the porosity in each individual specimen (not necessarily the total porosity) certainly plays a role in the variation between samples.

In Figure 3, the thermal conductivity values for each of the unirradiated fiber reinforced composites (see Table 1) are compared. For clarity, the individual data points for the two composites with the CVI SiC matrix (shown in Figure 2) have been replaced by best-fit curves. The thermal conductivity values appear to be separated into three distinct groups, primarily dependent on the matrix material. The CVI SiC is the most crystalline and stoichiometric matrix, which leads to 
thermal conductivity values approximately a factor of five greater than obtained for composites with the less crystalline and less stoichiometric PIP SiC matrix. Further, the thermal conductivity values for the PIP SiC matrix composites are approximately a factor of two higher than the Blackglas matrix composites. No noticeable thermal conductivity dependence on the type of fiber or interface could be discerned from these data.

In Figure 4, the thermal conductivity values as a function of measurement temperature for Nicalon/150 nm PyC/CVI SiC composites irradiated at different temperatures and doses are presented. The irradiation temperatures nominally ranged between 500 and $1000^{\circ} \mathrm{C}$, and the doses ranged between 4.3 and $43 \mathrm{dpa}-\mathrm{SiC}$; thermal conductivity appears to be relatively independent of dose for a given irradiation temperature. Values obtained from diffusivity data recorded on heating are indicated by solid lines, while those for data recorded on cooling are shown by dashed lines. Initially, the values for the 800 and $1000^{\circ} \mathrm{C}$ irradiations are similar $(\approx 3 \mathrm{~W} / \mathrm{m}-\mathrm{K})$ and significantly reduced compared to values for the unirradiated composite $(\approx 9 \mathrm{~W} / \mathrm{m}-\mathrm{K})$. The initial values for the composite irradiated at $500^{\circ} \mathrm{C}$ are even lower, at $2.2 \mathrm{~W} / \mathrm{m}-\mathrm{K}$. These initial values are relatively constant as a function of measurement temperature, until the measurement temperature exceeds the apparent irradiation temperature. For measurement temperatures greater than the irradiation temperature, the thermal conductivity values steadily increase. On cooling from the maximum measurement temperature $\left(\approx 1150^{\circ} \mathrm{C}\right)$, the thermal conductivity for all the irradiated composites in Figure 4 , independent of irradiation temperature and dose, attain a similar value of about $4 \mathrm{~W} / \mathrm{m}-\mathrm{K}$.

Heat transport through $\mathrm{SiC}$ occurs primarily via lattice vibrations (phonon conduction). The thermal conductivity of $\mathrm{SiC}$ is therefore very sensitive to the presence of point defects such as impurities, vacancies, or interstitials. At irradiation temperatures below the void formation temperature $\left(120{ }^{\circ} \mathrm{C}\right.$ for $\left.\mathrm{SiC}\right)$, the dominant defect responsible for scattering phonons is irradiation-induced point defects. Thus, the measurement of thermal conductivity is an effective method for inferring the presence of point defects in SiC. Point defect creation and annihilation occur simultaneously during irradiation. As irradiation temperature increases, the rate of annihilation increases while the rate of creation is unchanged. Therefore, the equilibium concentration of point defects decreases as irradiation temperature increases. Furthermore, the equilibrium defect concentration is attained relatively quickly ( $<1 \mathrm{dpa}-\mathrm{SiC}$ ), which explains the apparent dose independence of this phenomena. Earlier studies have shown that the reduction in thermal conductivity caused by the presence of the point defects may be eliminated by annealing the material above the irradiation temperature [17]. Presumably, this allows interstitials to become mobile and recombine with vacancies, thus eliminating phonon scattering sites and improving the conductivity of the irradiated material. The recovered thermal conductivity appears to primarily depend on the maximum annealing temperature, and not on the magnitude of the initial reduction caused by the irradiation. The increased thermal conductivity exhibited by the samples in 
Figure 4 after the post-irradiation anneal at $1150^{\circ} \mathrm{C}$ clearly demonstrates the thermal conductivity recovery behavior above the irradiation temperature.

The thermal conductivity recovery behavior illustrated in Figure 4 for the two composites nominally irradiated at $1000{ }^{\circ} \mathrm{C}$ suggests that the equilibrium concentration of point defects is more characteristic of a lower irradiation temperature. In Figure 5, the EBR-II power history during the last week of the irradiation cycle is depicted. The shaded area represents the time required to achieve $0.1 \mathrm{dpa}-\mathrm{SiC}$ near the reactor midplane. Apparently, operation of the reactor at reduced power for the three short intervals was sufficient to superimpose a defect structure more representative of a lower irradiation temperature over the defect structure resulting from the $1000{ }^{\circ} \mathrm{C}$ portion of the irradiation cycle. In fact, a pair of passive CVD $\beta$-SiC temperature monitor bars indicated an apparent irradiation temperature of $575 \pm 60^{\circ} \mathrm{C}$, via the isochronal annealing method. The bars were annealed at successively higher temperatures, and their lengths were measured after each anneal. When the annealing temperature exceeded the apparent irradiation temperature, the bar lengths decreased due to annihilation of point defects, and resultant recovery of the irradiation-induced swelling. The apparent irradiation temperature was determined from the bar length recovery measurements. After the final anneal at $1450{ }^{\circ} \mathrm{C}$ ( 3 hours), the length recovery was only $50 \%$. Using the same technique, Price observed $85 \%$ swelling recovery for $\mathrm{SiC}$ bars annealed at $1500^{\circ} \mathrm{C}$ after irradiation at $800^{\circ} \mathrm{C}$ [18]. The high level of residual swelling observed in the present study after the $14500^{\circ} \mathrm{C}$ anneal is indicative of a substantial quantity of more stable defects remaining, presumably a result of the $1000^{\circ} \mathrm{C}$ portion of the irradiation cycle. Thus, in this study, the thermal conductivity obtained during the cooling portion of the measurement cycle, rather than the heating portion, should be more representative of as-irradiated values expected for a nominal irradiation temperature of $1000^{\circ} \mathrm{C}$. All the other composites examined in this study exhibited similar thermal conductivity recovery behavior. Therefore, their thermal conductivity values determined during the cooling portion of the measurement cycle also should be more representative of the expected as-irradiated values for a $1000{ }^{\circ} \mathrm{C}$ irradiation temperature.

In Figure 6, the thermal conductivity of unirradiated and irradiated Nicalon/150 $\mathrm{nm} \mathrm{PyC} / \mathrm{CVI} \mathrm{SiC} \mathrm{composites} \mathrm{as} \mathrm{a} \mathrm{function} \mathrm{of} \mathrm{irradiation} \mathrm{temperature} \mathrm{and} \mathrm{dose} \mathrm{is}$ presented. The $1000^{\circ} \mathrm{C}$ thermal conductivity shown is the hypothesized appropriate level (i.e., that determined during the cooling portion of the measurement cycle). The thermal conductivity values for the composites irradiated at 500, 800, and 1200 ${ }^{\circ} \mathrm{C}$, determined during the heating portion of the measurement cycle, are reproduced from Hollenberg, et al. [1]. The curves shown in Figure 6 should be representative of the as-irradiated thermal conductivity for Nicalon/150 nm PyC/CVI SiC composites. These data clearly demonstrate the irradiation temperature dependence of thermal conductivity due to the presence of irradiationinduced point defects. 
Figure 7 presents thermal conductivity values for Nicalon/150 nm PyC/CVI SiC composites in the unirradiated, thermal annealed, and irradiated conditions. The conductivity of the thermal annealed sample was approximately $12 \%$ lower than the unirradiated sample. The lower conductivity of the thermal annealed sample may be attributed to a slight degradation due to the thermal treatment at $1010^{\circ} \mathrm{C}$. The conductivity of the as-irradiated samples was approximately $50 \%$ lower than the unirradiated conductivity. Nevertheless, the most significant reduction in thermal conductivity was due to the irradiation, and not the thermal exposure.

Figure 8 presents thermal conductivity values for Nicalon/150 nm PyC/PIP SiC composites in the unirradiated, thermal annealed, and irradiated conditions. No significant differences in the thermal conductivity values were observed between the unirradiated and the thermal annealed condition. However, the thermal conductivity values for the irradiated sample were approximately $36 \%$ higher than the unirradiated condition. Annealing the irradiated sample at $1150^{\circ} \mathrm{C}$ for one hour produced a further conductivity increase of approximately $13 \%$. Although the PIP $\mathrm{SiC}$ matrix composite exhibits improved thermal conductivity after irradiation, its conductivity remains approximately $35 \%$ lower than the CVI SiC matrix composites in the $\left(1000^{\circ} \mathrm{C}\right)$ irradiated condition (as represented by the diffusivity data obtained during the cooling portion of the measurement cycle).

Figure 9 presents thermal conductivity data for Nicalon/150 nm PyC/Blackglas composites in the unirradiated and irradiated conditions. No thermal annealed specimen was available. The conductivity of the as-irradiated specimens averaged about 35\% higher than the unirradiated sample. Annealing for one hour at $1150^{\circ} \mathrm{C}$ produced a further increase in conductivity of approximately $18 \%$. In the asirradiated condition, the Blackglas matrix composites exhibit average conductivities 44\% lower than the PIP SiC composites and 62\% lower than the CVI SiC composites.

The behavior of the PIP SiC and Blackglas matrix composites is similar, in that both exhibit increases in conductivity after irradiation. The thermal conductivity values for the Blackglas composites are typical of an amorphous solid such as $\mathrm{SiO}_{2}$ glass, while the irradiation behavior of the CVI SiC composites is more analogous to quartz. Neutron irradiation has been shown to slightly improve the thermal conductivity of $\mathrm{SiO}_{2}$ glass, while decreasing the conductivity of quartz [19]. Thus, the dominant mechanism responsible for the increases in conductivity must be crystallization of the matrix during irradiation.

\subsection{Particulate reinforced composites}

Figure 10 presents thermal conductivity values for $\mathrm{SiC}_{\mathrm{w}} / \mathrm{CVI} \mathrm{SiC} \mathrm{composites} \mathrm{in}$ the unirradiated, thermal annealed, and irradiated condition. The short-term thermal stability of the samples was good, with neither the unirradiated nor the thermal annealed specimens displaying any difference in conductivity between the increasing and decreasing temperature legs. The thermal conductivity of the thermal annealed sample averages $22 \%$ lower than the unirradiated specimen, 
possibly due to the fact that the density of the thermal annealed specimen is $5 \%$ lower than the unirradiated sample. The conductivity of the irradiated specimens shows no dose dependence and averages $41 \%$ of the unirradiated sample at $400{ }^{\circ} \mathrm{C}$. Again, the representative thermal conductivity for the $\left(1000^{\circ} \mathrm{C}\right)$ irradiated composite is taken as the values established during the cooling leg of the measurement cycle. The relative degree of conductivity degradation and recovery exhibited by the irradiated samples is similar to that of the irradiated Nicalon/150 $\mathrm{nm}$ PyC/CVI SiC composites. However, the conductivity of the whisker-reinforced composites is roughly a factor of three higher than the fiber-reinforced composites in each of the three conditions. This is presumably due to the absence of planar voids and a significant contribution to the conductivity from the whisker reinforcement, in contrast to the fiber reinforced composites.

Figure 11 presents thermal conductivity data for $\mathrm{SiC}_{\mathrm{p}} /$ Blackglas composites in the unirradiated and irradiated condition. No difference in conductivity was observed between the two irradiated specimens after the $1150^{\circ} \mathrm{C}$ anneal. The conductivity was reduced by the irradiation to an average of $45 \%$ of the unirradiated value at $400{ }^{\circ} \mathrm{C}$. The $\mathrm{SiC}$ particulate reinforcement appears to contribute significantly to the conductivity of this composite, based on observing much higher conductivity values for $\mathrm{SiC}_{\mathrm{p}} /$ Blackglas than for Nicalon/150 nm PyC/Blackglas.

\subsection{Monolithic ceramics}

Figure 12 presents thermal conductivity data for $\mathrm{CVD} \beta-\mathrm{SiC}$ in the unirradiated, thermal annealed, and irradiated conditions. The thermal treatment clearly had no detrimental effect on thermal conductivity. The conductivity of the irradiated sample was reduced to an average of $26 \%$ of the unirradiated value after annealing for one hour at $1150^{\circ} \mathrm{C}$. The unirradiated conductivity of this material was very high compared to the CVI SiC matrix composites due to its high density, crystallinity, and purity. Thus, the as-irradiated conductivity of CVD $\beta$-SiC exceeds that of Nicalon/150 nm PyC/CVI SiC by a factor of five and $\mathrm{SiC}_{\mathrm{w}} / \mathrm{CVI} \mathrm{SiC} \mathrm{by} \mathrm{a} \mathrm{factor}$ of two.

Figures 13 and 14 present thermal conductivity data for Hexoloy SA and SX, respectively, in the unirradiated, thermal annealed, and irradiated conditions. Neither material displayed any conductivity degradation due to short- or long-term thermal exposure. In addition, no dose dependence was observed for either of the materials irradiated to 33 or $43 \mathrm{dpa}-\mathrm{SiC}$. The conductivity of Hexoloy SA is consistently higher than Hexoloy SX in each of the three conditions. The higher conductivity of Hexoloy SA is attributed to the use of a B sintering aid in contrast to the $\mathrm{Y}_{2} \mathrm{O}_{3}$ sintering aid used in Hexoloy SX. Other studies have reported that sintered $\mathrm{SiC}$ with B dopants exhibit improved thermal conductivity [20]. 


\subsection{Fundamental mechanisms responsible for conductivity degradation}

In general, the thermal conductivity of the crystalline materials tested in this study monotonically decreases as test temperature increases due to the intrinsic phonon-phonon scattering. The lower thermal conductivity values and the temperature independence typically displayed by the irradiated samples indicates the significant contribution of point defect scattering which becomes the dominant conductivity-limiting factor in most cases. Further, the magnitude of the conductivity degradation depends on the irradiation temperature (see Figure 6); the magnitude of the conductivity degradation decreases with increasing irradiation temperature.

Price [17] and others have suggested that the creation of interstitial-vacancy pairs during irradiation is responsible not only for the conductivity degradation, but also the bulk swelling observed in $\mathrm{SiC}$. The phonon mean free path in a lattice conductor may be estimated by two independent methods: from thermal conductivity data, and from irradiation-induced-swelling data. Price [17] and Hollenberg et al. [1] demonstrated that the phonon mean free paths calculated by each method were of the same order of magnitude. Based on these observations, they concluded that the vacancy-interstitial pairs created during irradiation were responsible for both the conductivity degradation and the irradiation-induced swelling. Furthermore, below a dose of approximately $25 \mathrm{dpa}-\mathrm{SiC}$ and an irradiation temperature of $1000^{\circ} \mathrm{C}$, both the irradiation-induced swelling and the thermal conductivity degradation in $\mathrm{SiC}$ have been shown to be relatively independent of dose.

Interstitials created by neutron bombardment coalesce to form small clusters at relatively low irradiation temperatures $\left(<1000^{\circ} \mathrm{C}\right)$ and doses $(<26 \mathrm{dpa}-\mathrm{SiC})$ [21]. Apparently, the equilibrium size of the clusters increases with increasing irradiation temperature, while the concentration of the clusters decreases [22]. Silicon carbide samples irradiated at $<1000^{\circ} \mathrm{C}$ have been observed to return to their pre-irradiation length after post-irradiation annealing at $1500^{\circ} \mathrm{C}$ [18]. This suggests that the interstitials that form these clusters recombine with vacancies during the postirradiation anneals at temperatures exceeding the irradiation temperature. For irradiation temperatures above $1000^{\circ} \mathrm{C}$, the large interstitial clusters that form are more stable and are not as likely to anneal out during post-irradiation thermal treatment.

Yano, et al. [22] observed the presence of dislocation loops (10 to $30 \mathrm{~nm}$ diameter) at moderate irradiation temperatures $\left(400\right.$ to $600^{\circ} \mathrm{C}$ ) and very high doses $(\approx 60 \mathrm{dpa}-\mathrm{SiC})$. For this type of irradiation-induced defect structure, the overall swelling was reduced compared to lower dose irradiations at the same temperature, while the lattice parameter was unchanged from the unirradiated condition. The more stable dislocation loop structure resulted in some residual swelling remaining even after post-irradiation anneals to $1500^{\circ} \mathrm{C}$. Thus, it is probable that at doses in excess of approximately $26 \mathrm{dpa}-\mathrm{SiC}$, the swelling of $\mathrm{SiC}$ (even below irradiation 
temperatures of $1000^{\circ} \mathrm{C}$ ) becomes dose dependent and irrecoverable by postirradiation anneals. Likewise, the thermal conductivity degradation would be expected to be somewhat dose dependent and irrecoverable for these irradiation conditions.

To further explore the nature of the thermal conductivity degradation and recovery, the irradiated CVD $\beta-S i C$ specimen was subjected to a series of postirradiation high-temperature anneals, as shown in Figure 15. After measuring the as-irradiated thermal diffusivity from 400 to $1000^{\circ} \mathrm{C}$, the sample was annealed for one hour at $1150^{\circ} \mathrm{C}$, and the thermal diffusivity was again measured from 400 to $1000^{\circ} \mathrm{C}$. This procedure was repeated for subsequent anneals at 1250,1350 , and $1450^{\circ} \mathrm{C}$. The data in Figure 15 indicate that a significant amount of residual conductivity degradation remained even after the $1450^{\circ} \mathrm{C}$ anneal. If the only defect structures present were vacancies and small interstitial clusters, the $1450^{\circ} \mathrm{C}$ anneal should have been sufficient to restore the conductivity of the sample to near unirradiated values.

A possible explanation for the observed behavior of the thermal conductivity recovery is the presence of a duplex defect structure established by the long-term $1000{ }^{\circ} \mathrm{C}$ irradiation, followed by a very short $575^{\circ} \mathrm{C}$ irradiation near the end of the cycle. The long-term $1000^{\circ} \mathrm{C}$ irradiation established a relatively stable network of interstitial type dislocation loops, while the short-term $575^{\circ} \mathrm{C}$ irradiation established a defect structure characterized by the smaller, less stable interstitial clusters. The vacancies for both types of interstitial defects remain relatively isolated and distributed throughout the lattice. The interstitial dislocation loops themselves are relatively coherent with the $\mathrm{SiC}$ crystal structure and are not expected to significantly degrade the thermal conductivity. The observed conductivity recovery that occurs between the as-irradiated and $1450^{\circ} \mathrm{C}$ annealed conditions is the result of recombining interstitials not bound in the stable dislocation loops with vacancies. The residual conductivity degradation must be caused by the remaining vacancies, scattered throughout the SiC lattice, which provide the most effective phonon scattering sites.

In Figure 16, the thermal conductivity degradation for all crystalline $\mathrm{SiC}$ and $\mathrm{CVI}$ $\mathrm{SiC}$ matrix composites examined in this study is compared with that observed by others. A useful way to express the degradation is through the ratio of the irradiated to the unirradiated thermal conductivity values $\left(\mathrm{k}_{\mathrm{irr}} / \mathrm{k}_{\mathrm{unirr}}\right)$ as a function of both irradiation and measurement temperature. The data of Thorne, et al. [23], Price [17], and Rohde [24] were for $\beta-S i C$, while the data of Hollenberg, et al. [1] were for a Nicalon/150 nm PyC/CVI SiC composite. Data points for the present work were for

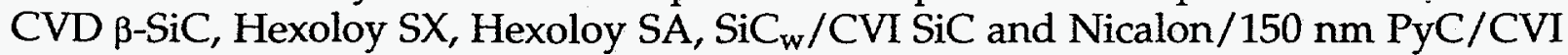
$\mathrm{SiC}$. Because the materials examined in this study experienced irradiation at both 575 and $1000^{\circ} \mathrm{C}$, two ratios were calculated for each material. At $575^{\circ} \mathrm{C}$, $\mathrm{k}_{\text {irr }}$ was determined from the heating portion of the diffusivity measurement cycle; at $1000^{\circ} \mathrm{C}, \mathrm{k}_{\mathrm{irr}}$ was determined from the cooling portion of the measurement cycle. The general trend is for the $\mathrm{k}_{\mathrm{irr}} / \mathrm{k}_{\mathrm{unirr}}$ ratio to increase as the irradiation temperature 
increases. Significantly, the ratios can be separated into a family of best-fit curves apparently depending upon purity, density, and probably microstructural features. In this separation, the curve for CVD $\beta-S i C$ has the lowest ratio at each temperature, and the curve through these data points approximately represents the intrinsic irradiation behavior of $\mathrm{SiC}$. In order of increasing ratios are curves for the dense, sintered Hexoloy materials, the $\mathrm{SiC}_{\mathrm{w}} / \mathrm{CVI} \mathrm{SiC}$ composite, and finally, the continuous fiber reinforced CVI SiC matrix composites. The curves are approximately parallel to each other except for the Hexoloy SA and SX curves. For these two materials, the curves appear to cross, with the Hexoloy SX ratio higher at $575^{\circ} \mathrm{C}$, and the Hexoloy SA ratio higher at $1000^{\circ} \mathrm{C}$. This observation probably reflects the difference in the structural details of the materials due to the $\mathrm{Y}_{2} \mathrm{O}_{3}$ doping (Hexoloy SX) or B-doping (Hexoloy SA).

From these curves, the thermal conductivity after irradiation of most crystalline $\mathrm{SiC}$-based materials can be predicted from measured values of unirradiated material. Furthermore, the temperature dependence of the thermal conductivity changes resulting from transient irradiation cycles can be predicted. Most importantly, these curves establish fundamental limits to processing strategies designed to enhance the thermal conductivity of irradiated $\mathrm{SiC}$-based materials. For example, B-doping of the CVI SiC matrix might be utilized to enhance Nicalon/CVI SiC thermal conductivity. However, no thermal conductivity values greater than those predicted for irradiated CVD $\beta$-SiC should be expected, and in fact, the values should be considerably less. The thermal conductivity degradation for irradiated SiC will always be dominated by the phonon scattering of irradiation-induced point defects, namely the vacancies. The larger the thermal conductivity enhancement through a processing strategy, the larger the relative degradation due to irradiation effects.

\section{SUMMARY AND CONCLUSIONS}

In the unirradiated condition, the thermal conductivity of the SiC-based materials tested in this study decreased with increasing temperature, which is expected when phonon-phonon scattering is the dominant contributor to thermal resistivity. After irradiation to 33 or $43 \mathrm{dpa}-\mathrm{SiC}$, the conductivity was degraded and was relatively temperature independent, which indicates that the thermal resistivity was then dominated by point-defect scattering. Because the conductivity was limited by temperature-independent point-defect scattering, the magnitude of irradiation-induced conductivity degradation was greater at lower temperatures and was typically more noticeable for materials with higher unirradiated conductivity. However, despite exhibiting the greatest amount of degradation, CVD $\beta-S i C$ displayed the highest conductivity in both the unirradiated and irradiated conditions.

The fiber-reinforced PIP SiC and Blackglas matrix composites exhibited increases in thermal conductivity after the irradiation. This appeared to be the result of irradiation-induced matrix crystallization. Despite the conductivity increases after 
irradiation, the PIP SiC and Blackglas matrix composites exhibited conductivities lower than comparable CVI SiC matrix composites.

Exposure to a 165 -day anneal at $1010^{\circ} \mathrm{C}$ did not appreciably degrade the thermal conductivity of any of the materials that were subjected to this treatment. The thermal conductivity of the fiber-reinforced polymer-derived matrix composites increased slightly during the anneal, presumably due to partial matrix crystallization.

In this study, over half the irradiated samples exhibited a minimum conductivity near $800{ }^{\circ} \mathrm{C}$. Above $800^{\circ} \mathrm{C}$, the conductivity increased, which indicated that annealing of irradiation-induced point defects was occurring. This was interpreted to be a result of three low-power cycles at the end of the full power, $1000^{\circ} \mathrm{C}$ irradiation. The time encompassed by these cycles was sufficiently long to increase the concentration of point defects in $\mathrm{SiC}$ to a level corresponding to a $575 \pm$ $60^{\circ} \mathrm{C}$ temperature during this period. Thus, the final irradiation defect structure is duplex, consisting of more stable interstitial dislocation loops and small, relatively unstable interstitial clusters together with their associated vacancies. The thermal conductivity degradation and recovery behavior reflect this hypothesis.

To further examine this contention, an irradiated CVD $\beta-S i C$ sample was subjected to a series of anneals at successively higher temperatures from 1150 to $1450^{\circ} \mathrm{C}$. The thermal conductivity partially recovered after each subsequent anneal; however, only about $50 \%$ recovery was achieved even after the $1450^{\circ} \mathrm{C}$ anneal. The irradiation damage induced at $1000^{\circ} \mathrm{C}$ consisted of stable dislocation loops, which contribute little to the thermal conductivity degradation. Thus, the residual conductivity degradation must be primarily caused by the remaining vacancies.

A useful way to express the thermal conductivity degradation for irradiated SiCbased materials is through the $\mathrm{k}_{\mathrm{irr}} / \mathrm{k}_{\text {unirr }}$ ratio map as a function of irradiation and measurement temperature. For design or operation of a fusion reactor system containing these materials, this map predicts the expected equilibrium thermal conductivity after irradiation. The map also sets limits on the amount of thermal conductivity enhancement one should expect from processing strategies.

\section{REFERENCES}

1. Hollenberg, G.W., C.H. Henager, G.E. Youngblood, D.J. Trimble, S.A. Simonsen, G.A. Newsome, and E. Lewis. 1995. "The Effect of Irradiation on the Stability and Properties of Monolithic Silicon Carbide and $\mathrm{SiC}_{\mathrm{f}} / \mathrm{SiC}$ Composites up to $25 \mathrm{dpa}$," J. Nucl. Mat., 219:70-86.

2. Woodford, D.A., D.R. Van Steele, J.A. Brehm, L.A. Timms and J.E. Palko. 1993. "Testing the Tensile Properties of Ceramic-Matrix Composites," JOM, 45(5):57-63. 
3. R.D. Cowan. 1961. "Proposed Method of Measuring Thermal Diffusivity at High Temperatures," I. Appl. Phys. 32:1363-1370.

4. W.J. Parker, R.J. Jenkins, C.P. Butler, and G.L. Abbot. 1961. "Flash Method of Determining Thermal Diffusivity, Heat Capacity, and Thermal Conductivity," J. Appl. Phys. 32:1679-1684.

5. J.A. Koski. 1981. "Improved Data Reduction Methods for Laser Pulse Diffusivity Determination with the Use of Minicomputers," In: Proceedings of the Eighth Symposium on Thermophysical Properties, Ed. J.V. Sengers, The American Society of Mechanical Engineers, New York.

6. J.A. Cape and G.W. Lehman. 1963. "Temperature and Finite Pulse-Time Effects in the Flash Method for Measuring Thermal Diffusivity," J. Appl. Phys. 34:1909-1913.

7. K.B. Larson and K. Koyama. 1967. "Correction for Finite-Pulse-Time Effects in Very Thin Samples Using the Flash Method of Measuring Thermal Diffusivity," J. Appl. Phys. 38:465-474.

8. R.C. Heckman. 1973. "Finite Pulse-Time and Heat-Loss Effects in Pulse Thermal Diffusivity Measurements," J. Appl. Phys. 44:1455-1460.

9. R.D. Cowan. 1963. "Pulse Method of Measuring Thermal Diffusivity at High Temperatures," J. Appl. Phy. 34:926-927.

10. L.M. Clark and R.E. Taylor. 1975. "Radiation Loss in the Flash Method for Thermal Diffusivity," J. Appl. Phys. 46:714-719.

11. D.A. Watt. 1966. "Theory of Thermal Diffusivity by Pulse Technique," Brit. J. Appl. Phys.. 17:221-240.

12. R.E. Taylor and J.A. Cape. 1964. "Finite Pulse-Time Effects in the Flash Diffusivity Technique," Appl. Phys. Lett. 17:321-240.

13. A. Cezairliyan. 1988. Specific Heat of Solids. Hemisphere Publishing Corporation, New York.

14. H.M. Rosenberg. 1965. Low Temperature Solid State Physics. Clarendon Press, Oxford, England.

15. R.A. Swalin. 1962. Thermodynamics of Solids. John Wiley and Sons, New York. 
16. Y.S. Touloukian and C.Y. Ho. 1972. Thermophysical Properties of Matter. Plenum Press, New York.

17. R.J. Price. 1973. "Thermal Conductivity of Neutron-Irradiated Pyrolytic $\beta-$ Silicon Carbide," J. Nucl. Mater. 46:268-272.

18. R.J. Price. 1972. "Annealing Behavior of Neutron-Irradiated SiC Temperature Monitors," Nucl. Tech. 16:536-592.

19. W.D. Kingery, H.H. Bowen and D.R. Uhlman. 1955. Introduction to Ceramics. John Wiley and Sons, New York.

20. Y. Takeda. 1988. "Development of High Conductive SiC Ceramics," Ceramic Bull. 67(12):1961-63.

21. T. Suzuki, T. Yano, T. Mori, H. Miyazaki and T. Iseki. 1995. "Neutron Irradiation Damage of Silicon Carbide," Fusion Tech. 27:314-325.

22. T. Yano, T. Suzuki, T. Maruyama and I. Iseki. 1988. "Microstructure and Annealing Behavior of Heavily Neutron-Irradiated $\beta$-SiC," J. Nucl. Mater. 155-157:311-314.

23. R.P. Thorne, V.C. Howard and B. Hope. 1967. "Radiation-Induced Changes in Porous Cubic Silicon Carbide," Proc. Brit. Cer. Soc. 7:449.

24. M. Rohde. 1991. "Reduction of the Thermal Conductivity of SiC by Radiation Damage," J. Nucl. Mater. 182:87-92. 


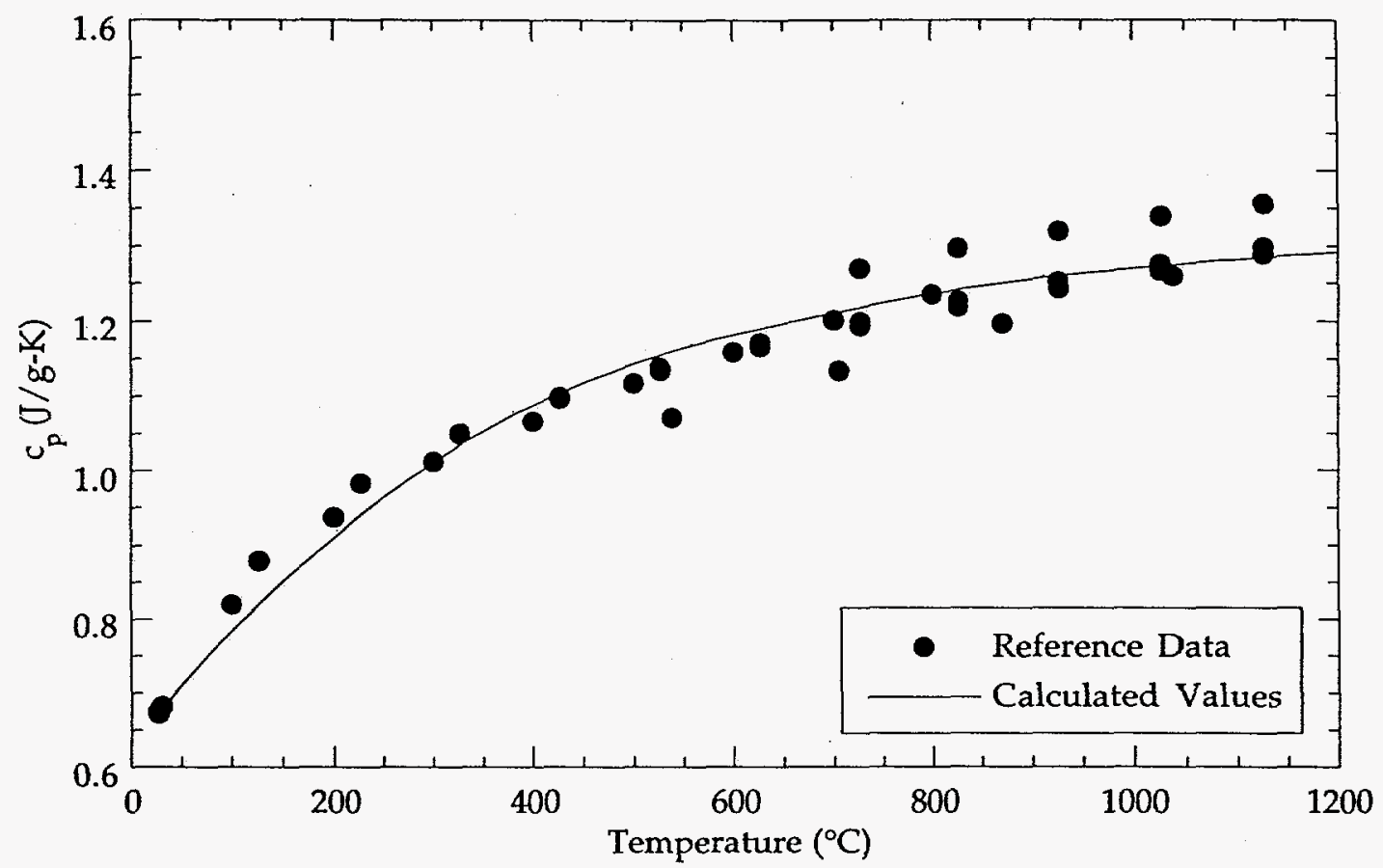

Figure 1. Comparison of calculated specific heat values with literature data [16] for $\mathrm{SiC}$.

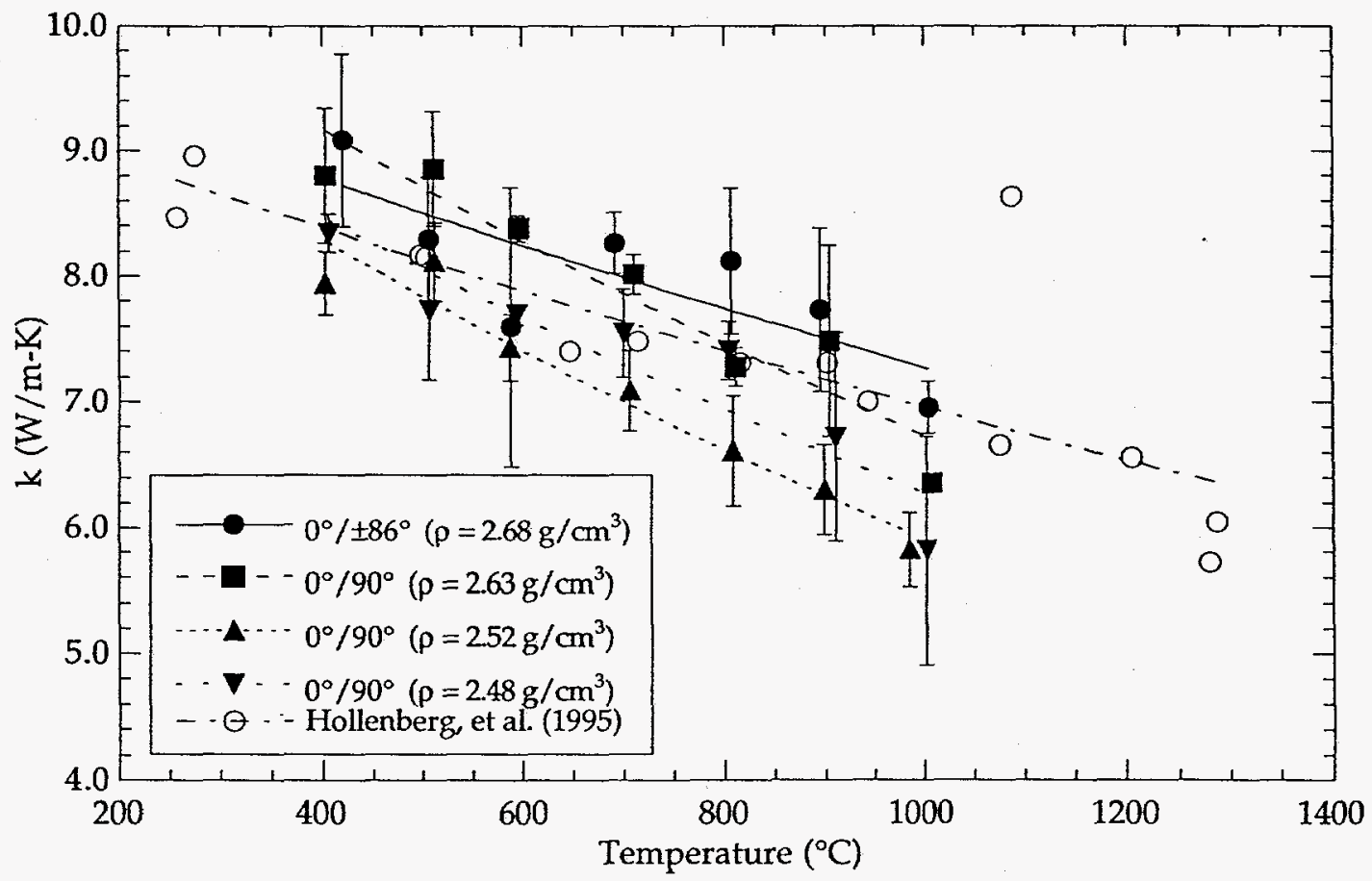

Figure 2. Calculated thermal conductivity values for unirradiated Nicalon $/ 150 \mathrm{~nm}$ $\mathrm{PyC} / \mathrm{CVI} \mathrm{SiC}$ composites with different fiber architectures and densities. The curves are included for guidance only. 


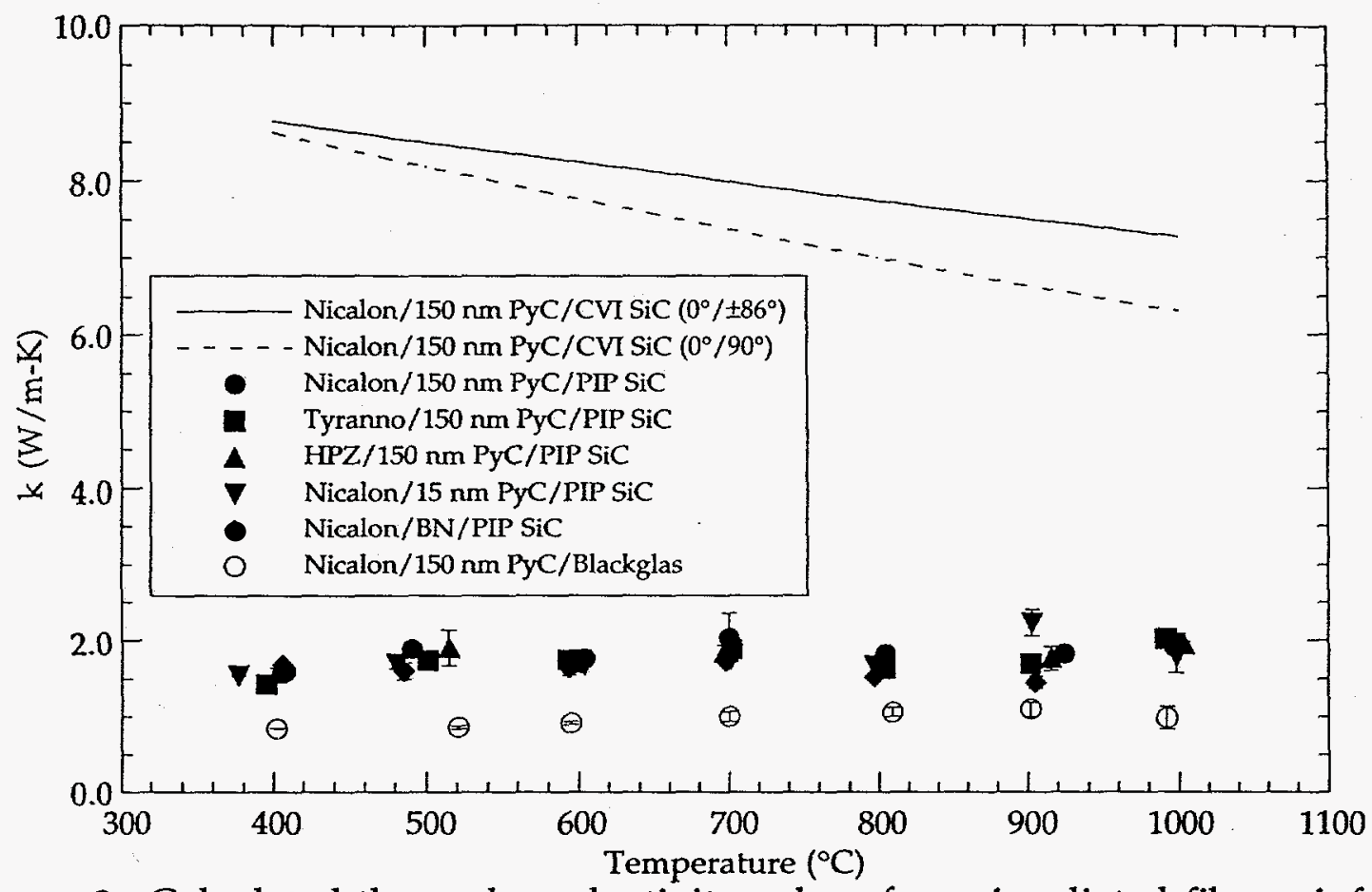

Figure 3. Calculated thermal conductivity values for unirradiated fiber reinforced composites with CVI SiC, PIP SiC and Blackglas matrix materials.

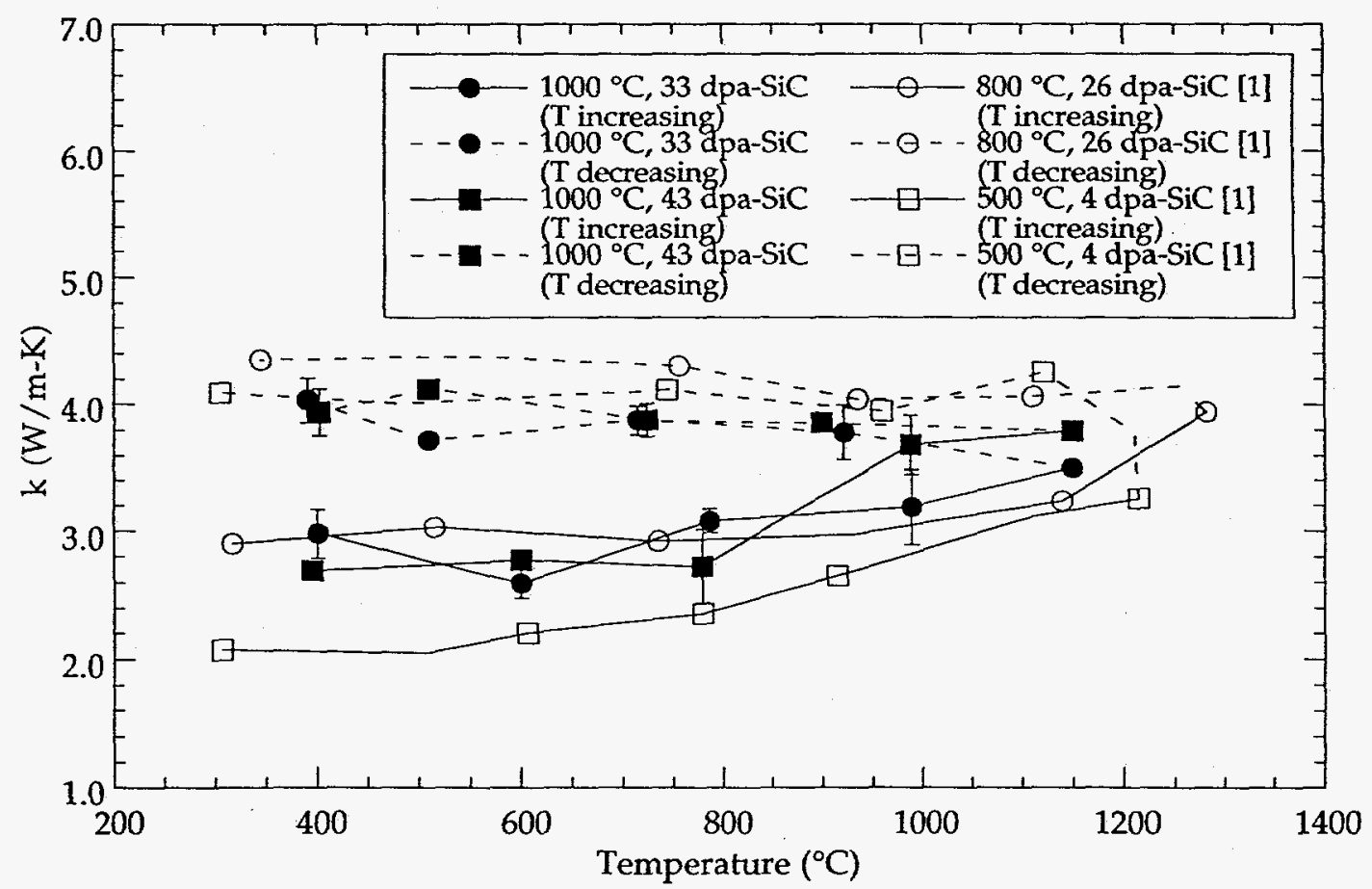

Figure 4. Thermal conductivity of Nicalon/150 nm PyC/CVI SiC composites irradiated at different temperatures and doses. 


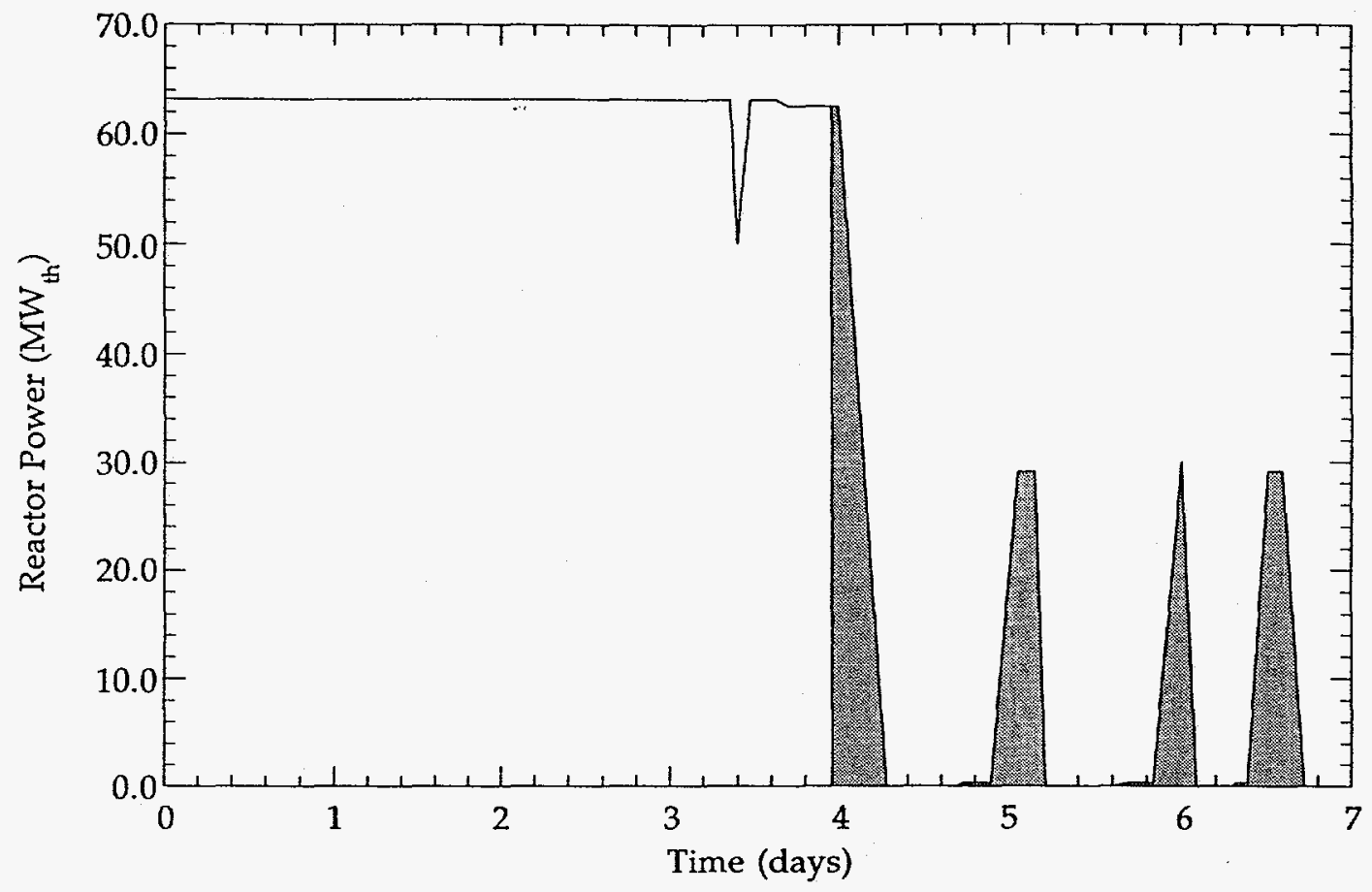

Figure 5. EBR-II Power History During Last Week of Irradiation Experiment. The shaded area represents the time required to achieve $0.1 \mathrm{dpa}-\mathrm{SiC}$ near the reactor midplane.

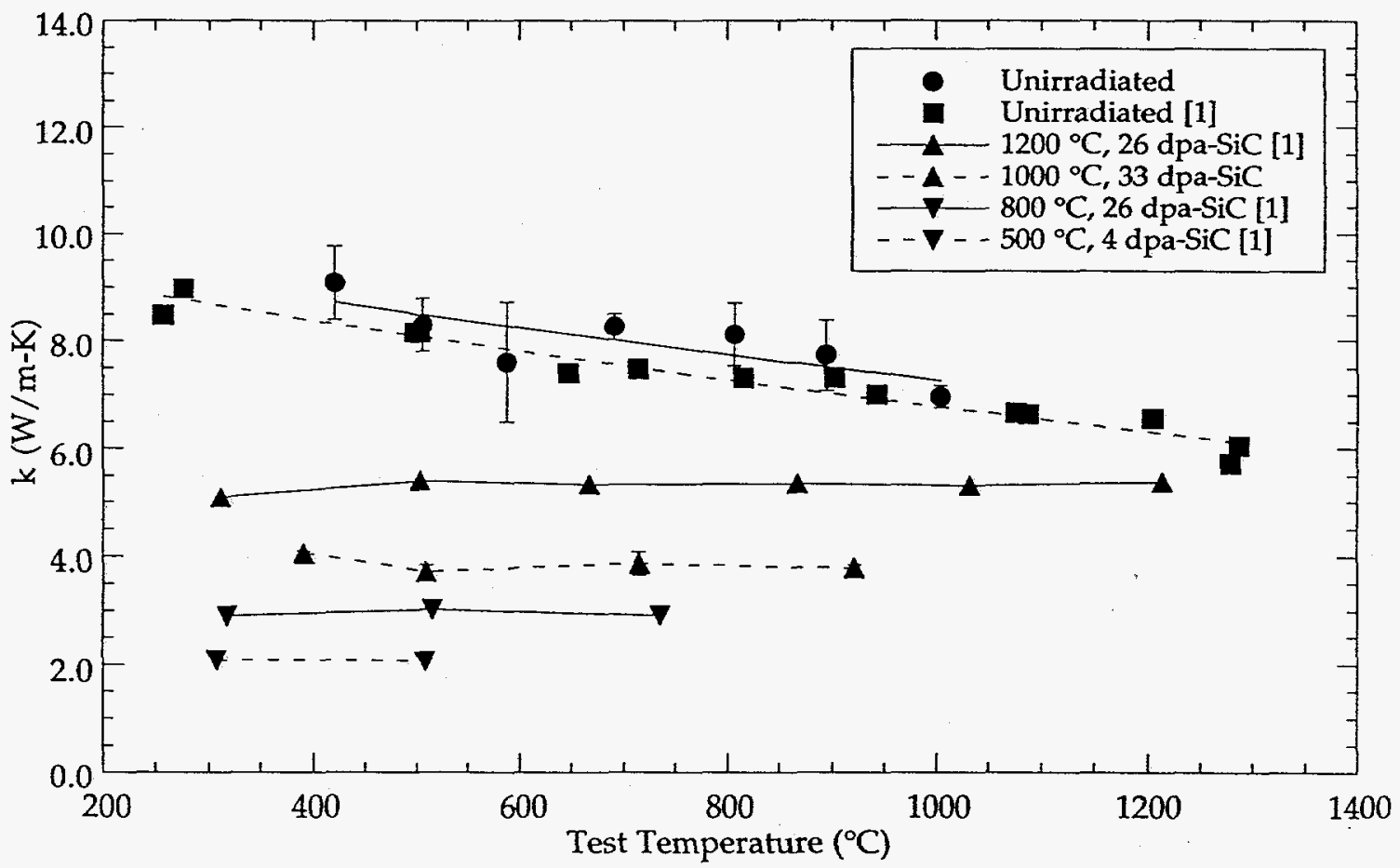

Figure 6. Thermal conductivity of Nicalon/150 $\mathrm{nm}$ PyC/CVI SiC composites as a function of irradiation temperature and dose. 


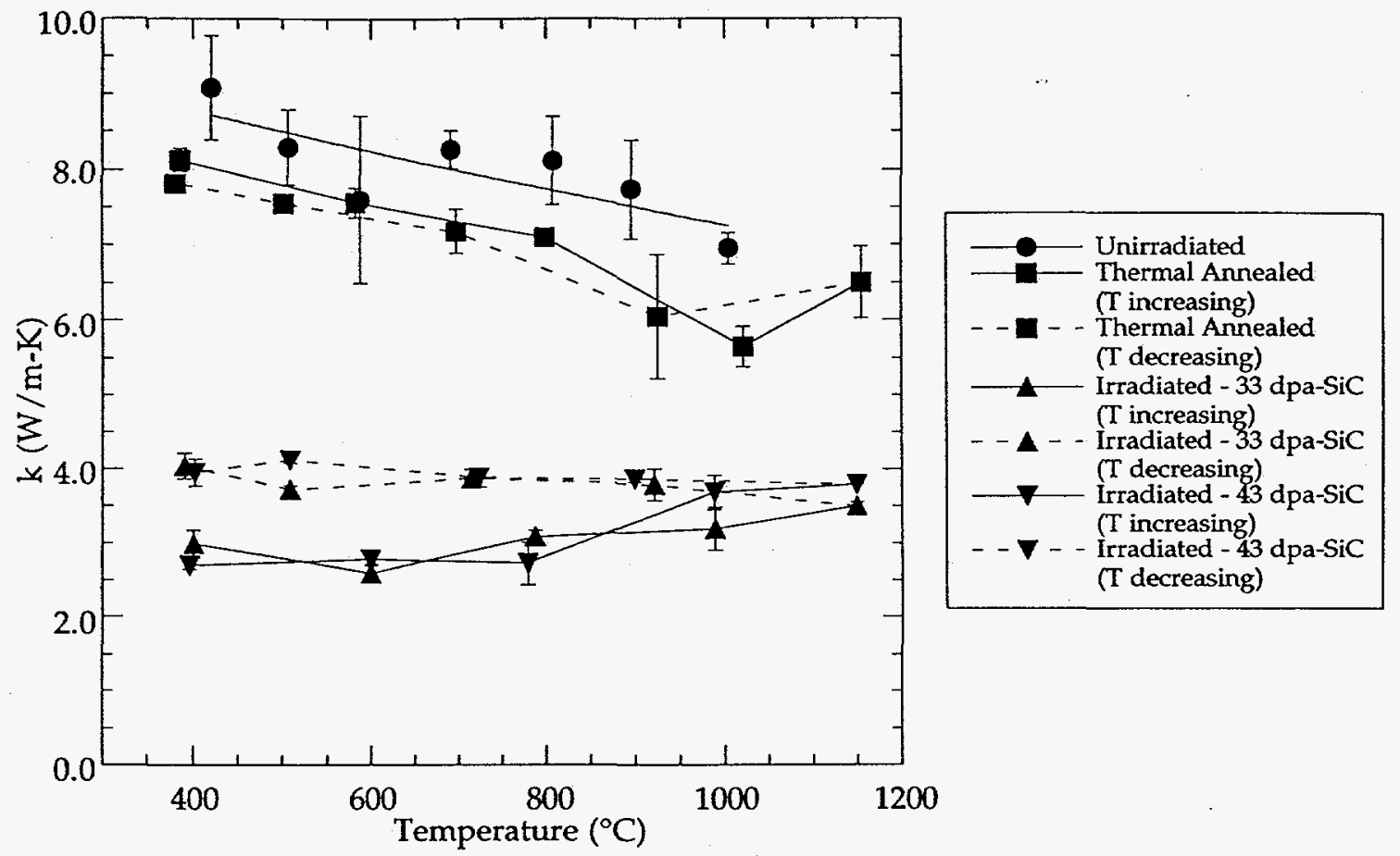

Figure 7. Effects of thermal treatment and irradiation on thermal conductivity of Nicalon/150 nm PyC/CVI SiC composites.
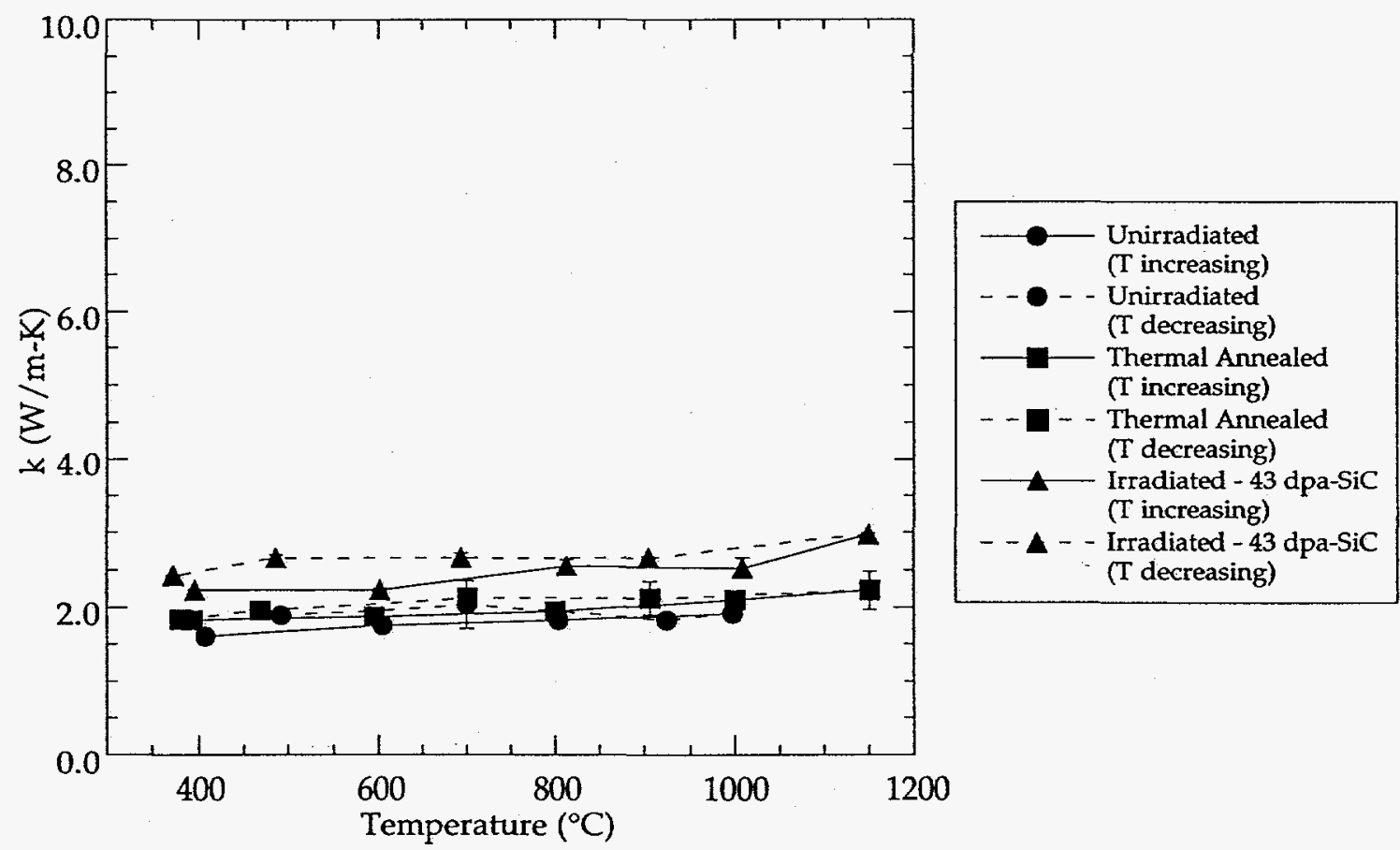

Figure 8. Effects of thermal treatment and irradiation on thermal conductivity of Nicalon/150 nm PyC/PIP SiC composites. 

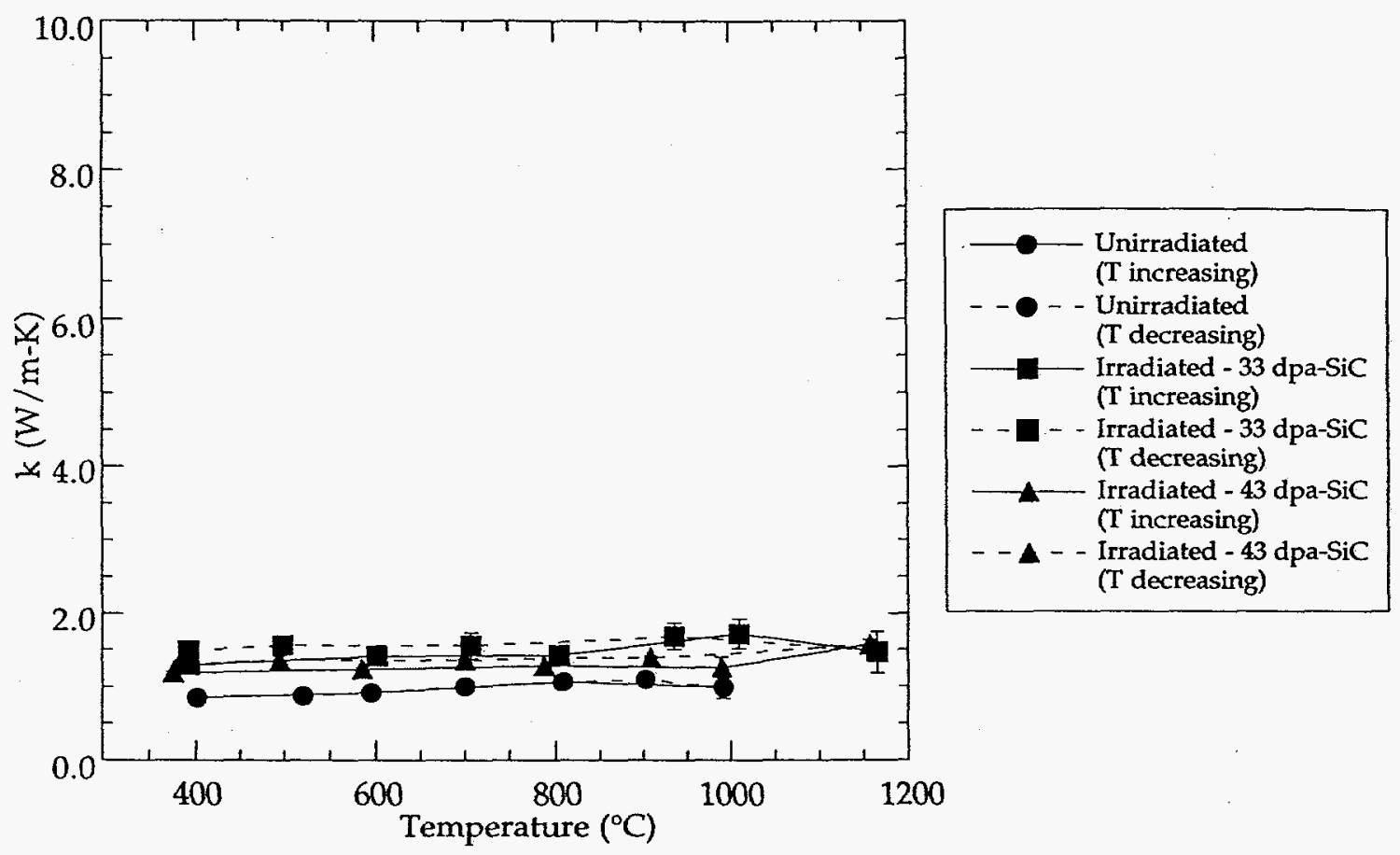

Figure 9. Effects of irradiation on thermal conductivity of Nicalon/150 nm PyC/Blackglas composites.
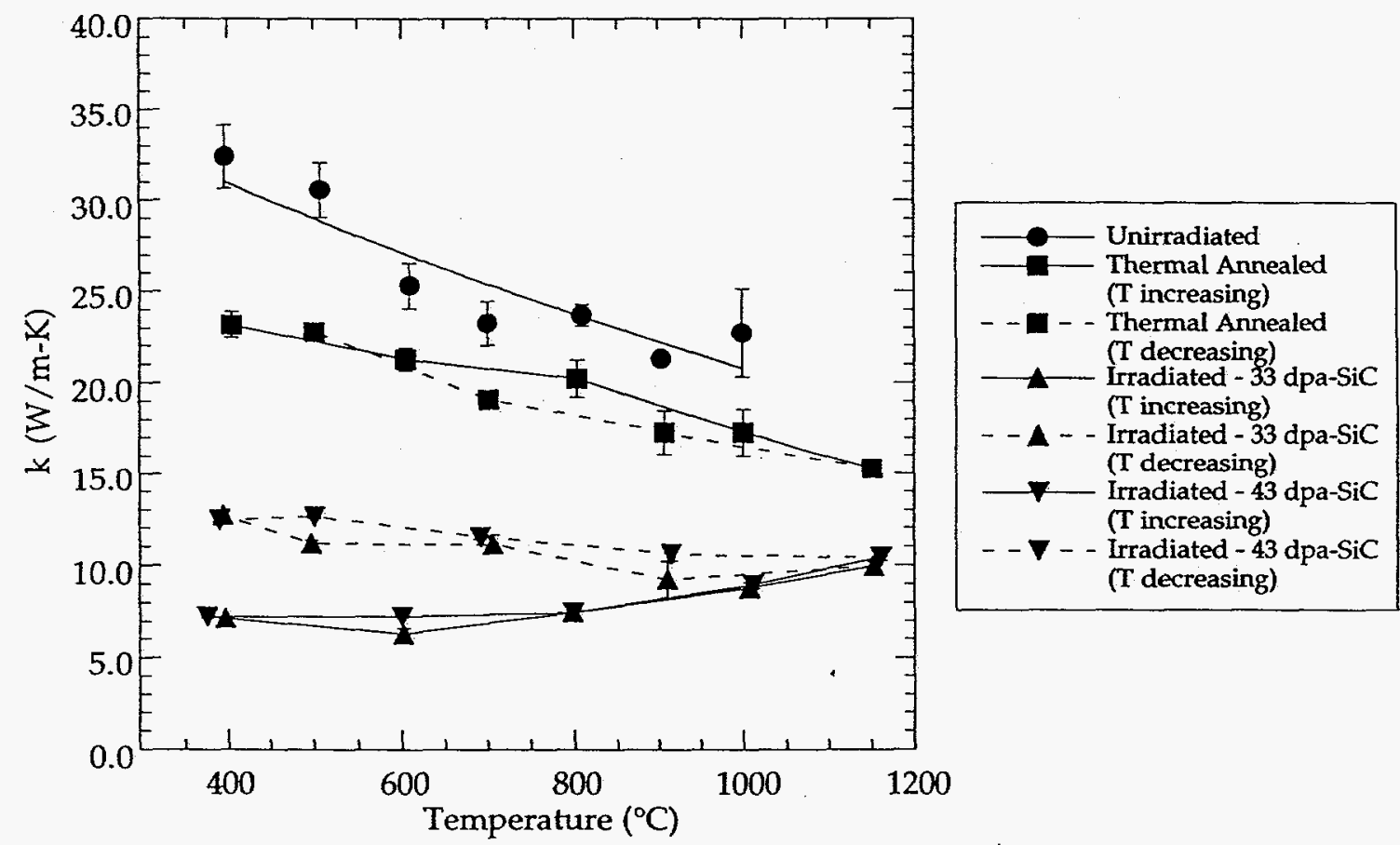

Figure 10. Effects of thermal treatment and irradiation on thermal conductivity of $\mathrm{SiC}_{\mathrm{w}} / \mathrm{CVI} \mathrm{SiC}$ composites. 


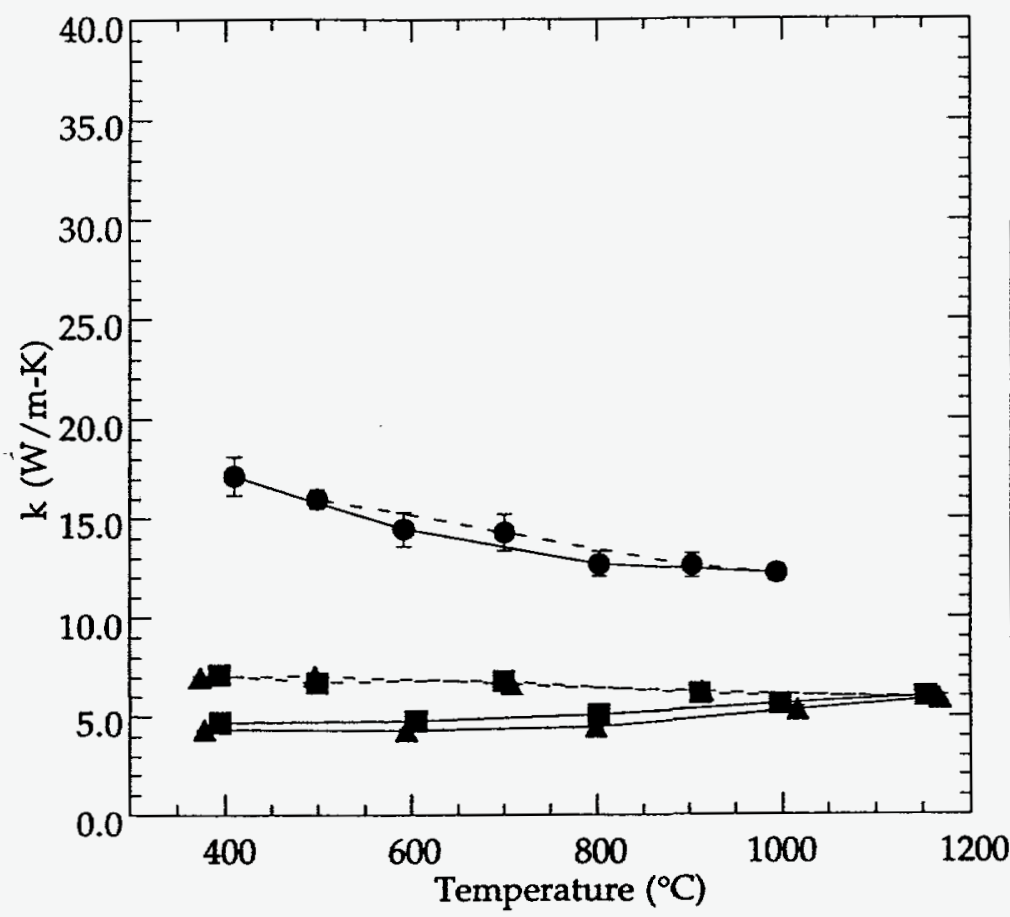

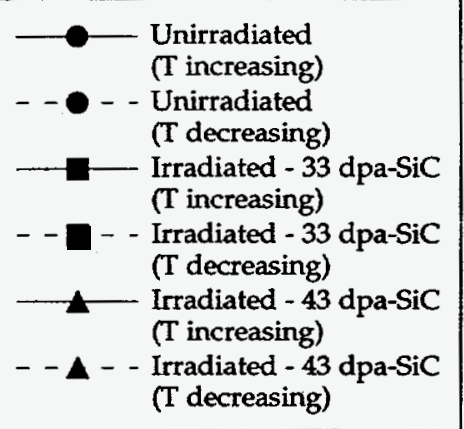

Figure 11. Effect of irradiation on thermal conductivity of $\mathrm{SiC}_{\mathrm{p}} /$ Blackglas composites.

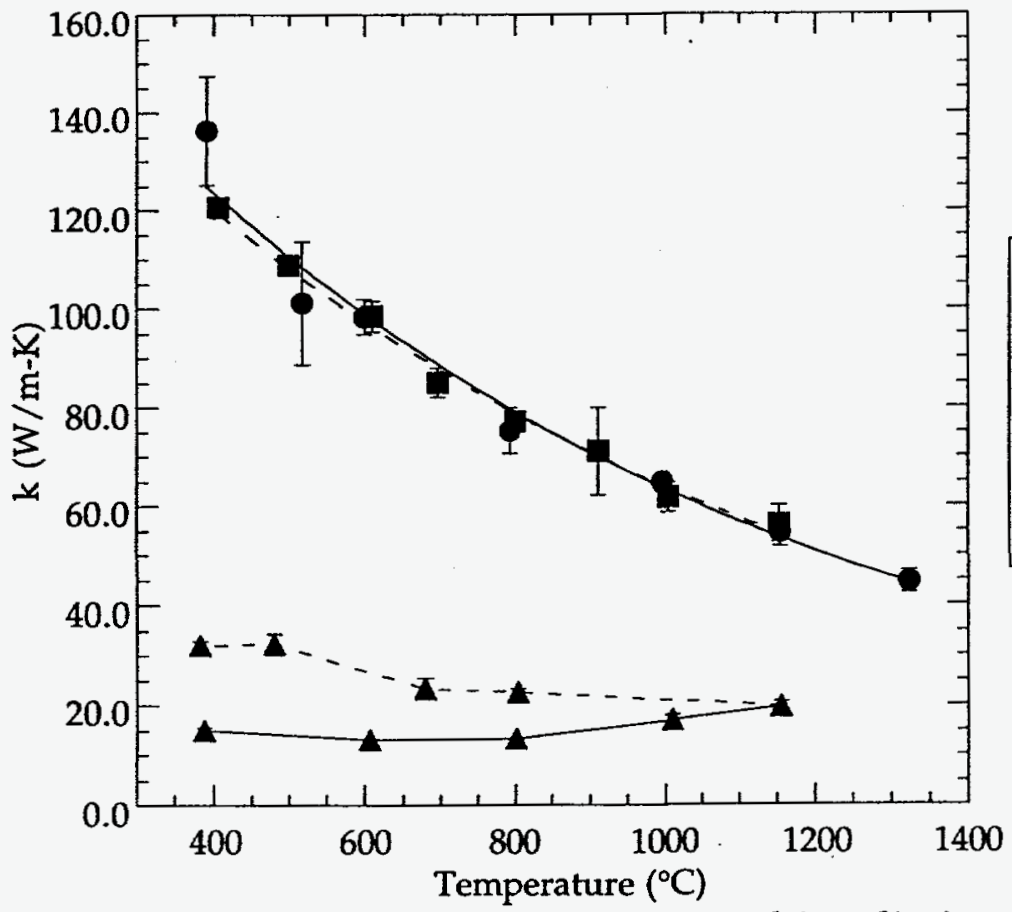

- Unirradiated

- - - Thermal Annealed

$\longrightarrow$ Irradiated - $33 \mathrm{dpa-SiC}$ ( $T$ increasing)

- - A - - Irradiated - 33 dpa-SiC (T decreasing)

Figure 12. Effect of thermal treatment and irradiation on thermal conductivity of CVD $\beta-S i C$. 

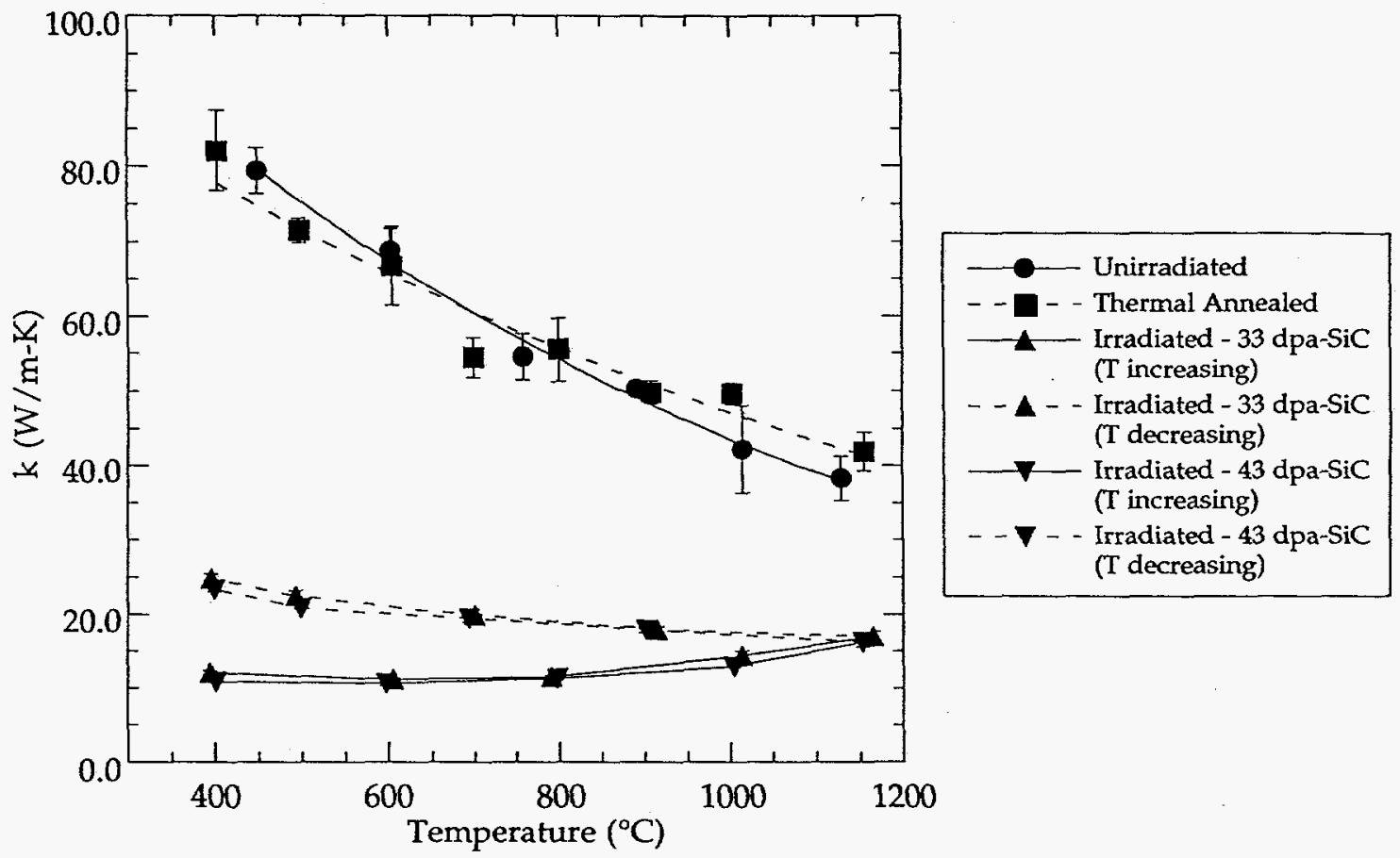

Figure 13. Effect of thermal treatment and irradiation on thermal conductivity of Hexoloy SA (B-doped).

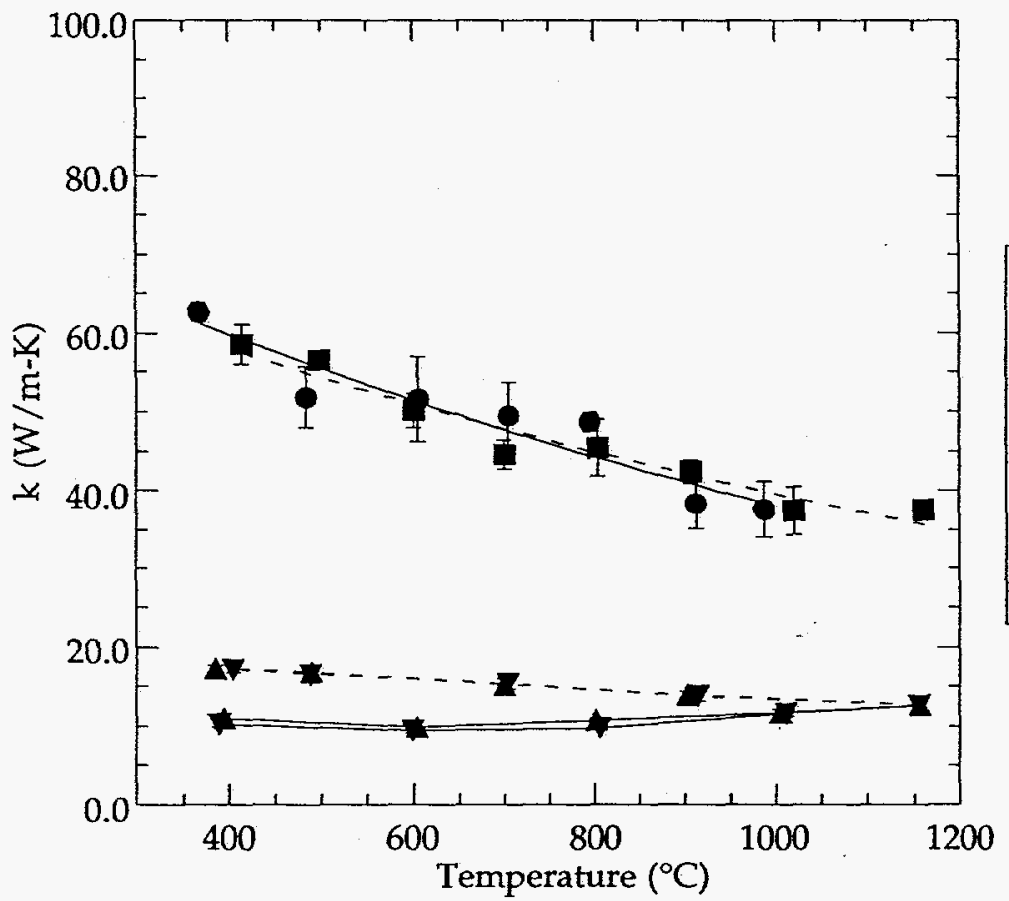

- Unirradiated

- - - Thermal Annealed

$\longrightarrow$ Irradiated - $33 \mathrm{dpa}-\mathrm{SiC}$ ( $T$ increasing)

- - A - - Irradiated - 33 dpa-SiC ( $\mathrm{T}$ decreasing)

$\longrightarrow$ - Irradiated - $43 \mathrm{dpa}-\mathrm{SiC}$ ( $T$ increasing)

- $\mathbf{T}$ - - Irradiated - $43 \mathrm{dpa}-\mathrm{SiC}$ ( $T$ decreasing)

Figure 14. Effect of thermal treatment and irradiation on thermal conductivity of Hexoloy $\mathrm{SX}\left(\mathrm{Y}_{2} \mathrm{O}_{3}\right.$-doped). 


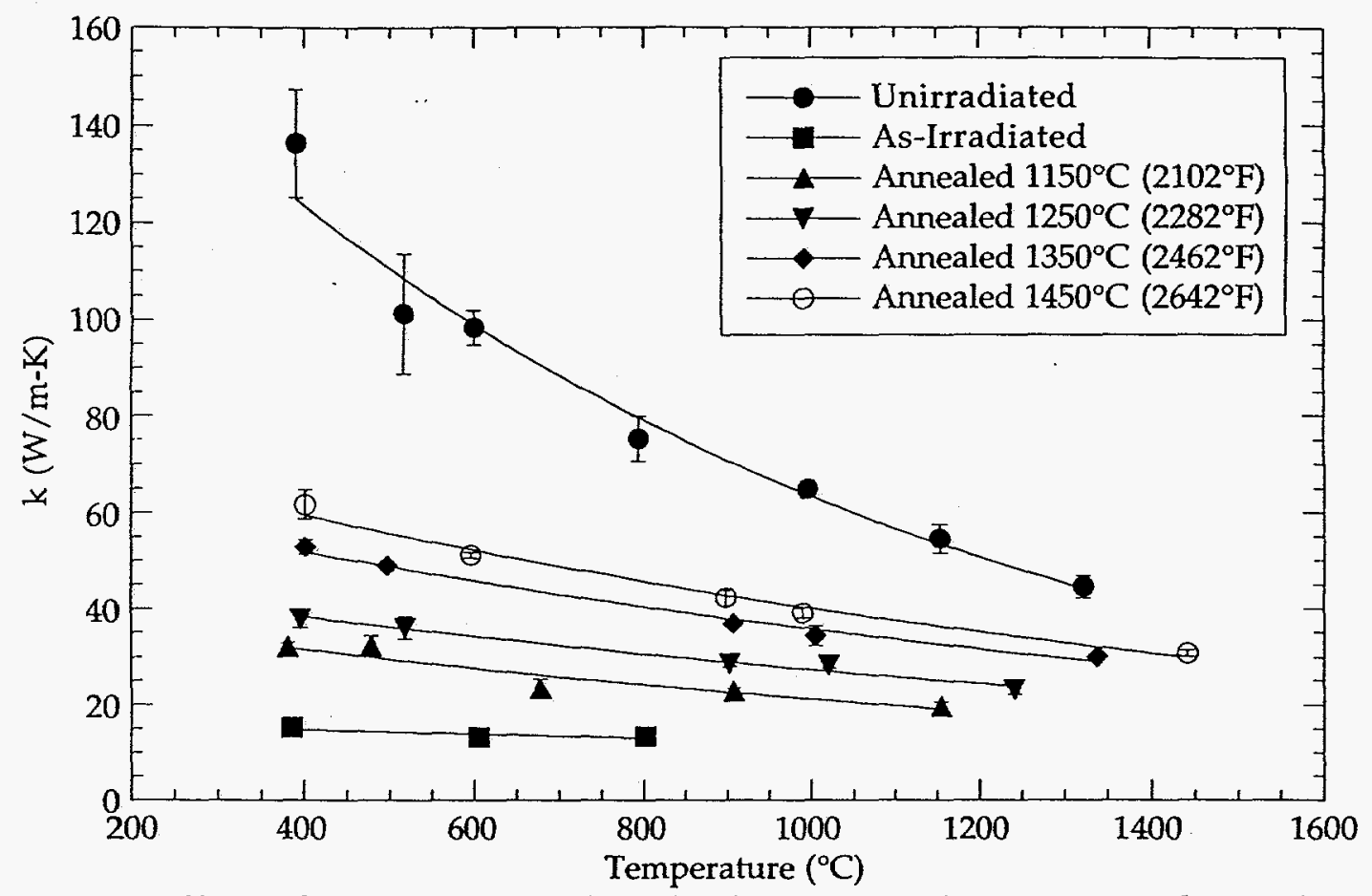

Figure 15. Effect of irradiation and multiple post-irradiation anneals on thermal conductivity of CVD $\beta-\mathrm{SiC}$.

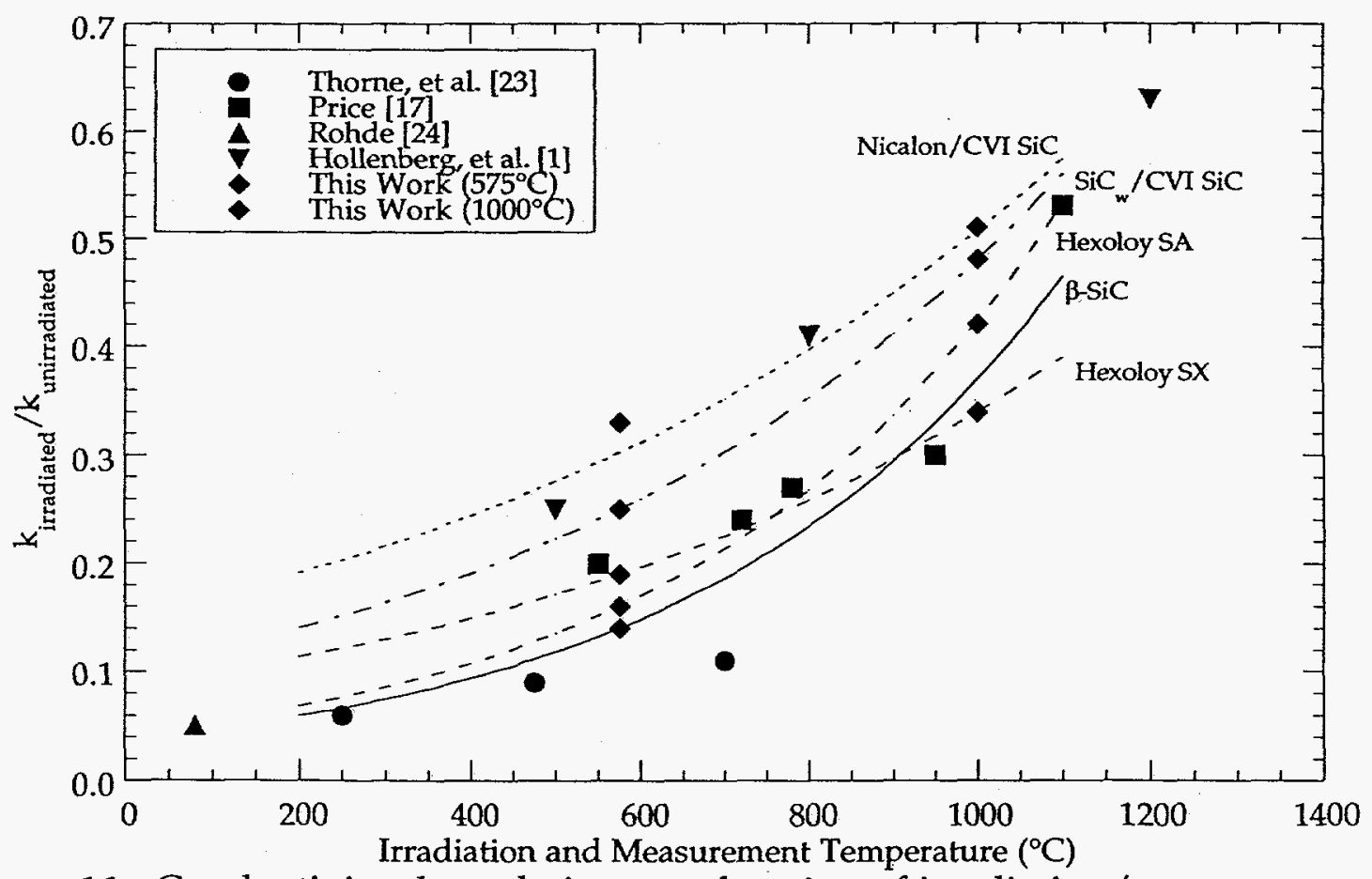

Figure 16. Conductivity degradation as a function of irradiation/test temperature for crystalline $\mathrm{SiC}$ and $\mathrm{CVI} \mathrm{SiC}$ matrix composites. 